\title{
HISTORY OF PRION PROTEIN GENE (PRNP) POLYMORPHISM IN SHEEP AND SCIENTIFIC FINDINGS
}

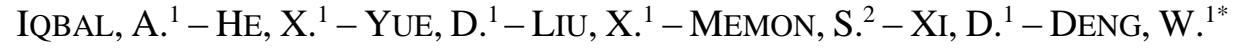 \\ ${ }^{I}$ Yunnan Provincial Key Laboratory of Animal Nutrition and Feed, Faculty of Animal Science \\ and Technology, Yunnan Agricultural University, Kunming, PR China \\ ${ }^{2}$ Yunnan Animal Science and Veterinary Institute, Kunming, PR China \\ *Corresponding author \\ e-mail: 1692425306@qq.com
}

(Received $15^{\text {th }}$ Dec 2019; accepted $25^{\text {th }}$ May 2020)

\begin{abstract}
Scrapie is basically a kind of disease that originally was specific to European countries, but from England it spread all over the world to Canada, South Africa, Australia, New Zealand and many other countries. Scrapie is a prion disease which is fatal and results in or can be characterized by the degeneration of the nervous system. It belongs to transmissible spongiform encephalopathies (TSEs) infecting small ruminants including sheep and goat. Sheep susceptibility or resistance to classical scrapie is highly supervised by the polymorphisms at codons 136,154 and 171 of the PRNP. In this review, we found that countries like Romania, Finland, Italy, Slovakia, Germany, Greece, Spain, Poland, Turkey, Iran, Brazil, England, Portugal, Hungary, Austria, and Czech Republic, are susceptible to scrapie, while in Pakistan, China, Algeria, West Africa, America, Burkina Faso, and Niger are those countries where sheep are not susceptible to this disease. From these studies, we can clearly conclude that China and Pakistan are the countries where sheep show more resistance to scrapie. We focused to summarize the PRNP polymorphism at 136, 154, and 171 in sheep and some important findings in major parts of the world.
\end{abstract}

Keywords: scrapie, transmissible spongiform encephalopathies (TSEs), European countries, history, prion

\section{Introduction}

Approximately, $70.7 \%$ of the total sheep population is present in Asia and $35.89 \%$ of the total population of sheep is present in China which has become the leading country for sheep products. But in China, no case of scrapie in sheep has been found so far, whereas in the countries like England, Greece, Turkey and other small European countries scrapie is on red alert. Where sheep (Ovis aries) and goat (Capra aegagrus hircus) have many resemblances, their scientific taxonomy eventually split, have distinct species and genus, whereas sheep and goat have 54 and 60 chromosomes simultaneously. The polymorphism of the PRNP gene plays a fundamental role in prion disease. Scrapie is resulting in or characterized by the degeneration of the nervous system affecting sheep and belongs to a group of a prion disease that naturally occurs in sheep. PRNP is responsible for negative influence on the financial loss, such as the cashmere yield, wool thickness (Lan et al., 2012) and milk yield (Vitezica et al., 2013) as well as the waistline, body length (Yang et al., 2016), rump length (Yang et al., 2018), and weight. Almost the same mutation of PRNP present in sheep, has also been determined in goat (White et al., 2008; Zhou et al., 2013). The only responsible factor for scrapie that has been determined until now is a prion. Scrapie is not like a viral or bacterial disease which have causal agent, rather it is a genetical disease making it difficult to cure. The possibility for the elimination of this disease is wholly associated with polymorphisms of the PRNP. Sheep and goat are not the only victims of prion disease as it has been reported in almost all vital living species of animals with different 
names (Table 1). The first human victimization to scrapie were the farmers or the sheep owners who were directly affected by the disease. During the 20th century, many ideas on the nature of the causative agent of TSEs were published (Table 2) while with the passage of time, the majority of these revealed to be unwarranted. Prion disease affects both animals and humans (Yaman and Ün, 2017) but until 1990s scientists failed to provide any evidence of transmission of disease to humans (Van Duijn et al., 1998).

Table 1. Affected species with prion diseases (Mabbott, 2017)

\begin{tabular}{c|c}
\hline Disease & Species \\
\hline Scrapie & Sheep, goats, mouflon \\
Iatrogenic Creutzfeldt-Jakob disease (CJD) & Human \\
Sporadic Creutzfeldt-Jakob disease & Human \\
Variant Creutzfeldt-Jakob disease & Human \\
Familial Creutzfeldt-Jakob disease & Human \\
Gerstmann-Straussler-Scheinker syndrome & Human \\
Kuru & Human \\
Fatal familial insomnia & Human \\
Bovine spongiform encephalopathy & Cattle \\
Chronic wasting disease & Elk, deer, moose \\
Transmissible mink encephalopathy & Mink \\
Feline spongiform encephalopathy & Domestic and zoological cats \\
Exotic ungulate encephalopathy & Nyala, kudu \\
\hline
\end{tabular}

Table 2. Names of causative agents given by different scientists from 1912 to 1991

\begin{tabular}{l|c|c}
\hline Year & TSE agents & Reference \\
\hline 1914 & Sarcosporidia & M'Gowan (1914) \\
1938 & A filterable virus & Cuillé and Chelle (1938) \\
1954 & A slow virus & Sigurdsson (1954) \\
1966 & A replicating polysaccharide & Alper et al. (1967) \\
1967 & A protein & Pattison and Jones (1967) \\
1967 & A replicating membrane & Gibbons and Hunter (1967) \\
1968 & A DNA-polysaccharide complex & Adams and Caspary (1968) \\
1972 & A viroid & Diener (1972) \\
1978 & A lipid & Alper et al. (1978) \\
1979 & A Spiroplasma sp. & Bastian (1979) \\
1979 & A virino & Dickinson (1979) \\
1982 & A prion & Prusiner (1982) \\
1984 & A virus & Manuelidis (1996) \\
1989 & Mitochondria (l nucleic acid(s)) & Aiken et al. (1990) \\
1991 & A holoprion, consisting of abnormal prp (PrP in the scrapie & Weissmann (1991) \\
\hline
\end{tabular}


Scrapie is the disease with the maximum and oldest publications as explicit journals allude to a paper going back to the year 1732 as the initial report of scrapie (Detwiler and Baylis, 2003). In 1772 scrapie was accounted for to be known for around 40 years, a point in time going back to the year 1732. This distemper disease is normally said to be remains of almost forty years in England (Comber, 1772). All scholars were devoted to the quest for the origin of the disease. A large number of proposed causes were diagnosed by all methods like the number of prescribed pathogens set forward all through the twentieth century. Since the 1930s, scrapie examination was reinforced when impressive money related misfortunes to the sheep business were brought about by expanding measurements of cases. These harms likewise advance studies on the precise idea of the infective reason, besides parasites (M'Gowan, 1914) and bacteria (Bastian, 1979) as causative agents, virus infection was the most frequently proposed principle, already formulated in 1938 (Cuillé and Chelle, 1938). In 1954, the word of a "slow virus infection" was presented the first time (Sigurdsson, 1954). Though, in 1966, a substitute to the viral origin was hypothesized as the cause, i.e., polysaccharides (Alper et al., 1966; Alper et al., 1967) or lipids (Alper et al., 1978). In 1967, for the first time, a protein was predictable as an infective cause (Pattison and Jones, 1967), and the first "protein-only- hypothesis" was articulated (Griffith, 1967), which was followed in the 1970s by the "virino" theory (Dickinson, 1979). At long last, in light of the opposition of the pathogen, in 1982, "proteinaceous irresistible molecule" (abbreviation: prion) was presented (Prusiner, 1982) and the transformation of a healthy cellular protein (PRPC) into a pathological isoform (PRPSc) as a critical event of TSE pathogenesis was proposed not long after (Oesch et al., 1985).

The investigation of scrapie was complex by the circumstance that in previous times, many new diseases like Drehkrankheit, Kreuzdrehe, and Gnubberkrankheit were confused with scrapie. Numerous scholars believed at least one of them to be indistinct with or separate from scrapie. Some particular authors attempted to recognize "Drehkrankheit," "Gnubberkrankheit," "Kreuzdrehe," and "Traberkrankheit." Whereas a lot of them segregate among "Drehkrankheit" and "Kreuzdrehe" from one viewpoint and "Traberkrankheit" on the other (Frank, 1820; Ribbe, 1821; Hering, 1849; Erdt, 1861; May, 1868), there were other writers who considered "Kreuzdrehe" and "Traberkrankheit" to be the identical but to be dissimilar from "Gnubberkrankheit" (Wagenfeld, 1829). This mistake of terms, just as the indistinct and confounding portrayal of the indications of scrapie and of different diseases, indicating scrapie recognized in the year 1750. Different terms that were utilized to make reference to scrapie are mentioned (Table 3).

Table 3. Historical names of scrapie given by locals in different regions of the world

\begin{tabular}{l|c|c|c}
\hline & Name of scrapie & Country & Reference \\
\hline $\mathbf{1}$ & Basquilla Disease & Spain & von Richthofen (1828) \\
$\mathbf{2}$ & Cuddie Trot & Scotland & Healy et al. (2003) \\
$\mathbf{3}$ & Drab(en) & Germany & von Richthofen (1827) \\
$\mathbf{4}$ & Dreb/Deeb & Germany & Frank (1820) \\
$\mathbf{5}$ & Drehkrankheit & Germany & Schneider et al. (2008) \\
$\mathbf{6}$ & Gaubber/G(n)aup(p)er & Germany & Schneider et al. (2008) \\
$\mathbf{7}$ & Gnubberkrankheit & Germany & Cassirer (1898) \\
$\mathbf{8}$ & Knopper & Germany & Frank (1820)
\end{tabular}




\begin{tabular}{|c|c|c|c|}
\hline 9 & Khujali & India & Katiyar (1962) \\
\hline 10 & $\operatorname{Kreu}(\mathrm{t}) \mathrm{zdrehe}(\mathrm{n})$ & Germany & von Richthofen (1827) \\
\hline 11 & Kreutzschlagen & Germany & Albert and Brunn (1818) \\
\hline 12 & La maladie convulsive & France & Liberski and Jaskólski (2002) \\
\hline 13 & La maladie foll(i)e & France & Beck et al. (1964) \\
\hline 14 & La maladie trotteurs & France & Besnoit (1899) \\
\hline 15 & La prurigo lombaire & France & Liberski and Jaskólski (2002) \\
\hline 16 & La Tremblante & France & Beck et al. (1964) \\
\hline 17 & Mukoo & India & Katiyar (1962) \\
\hline 18 & Petermännchen & Germany & Erdt (1861) \\
\hline 19 & Prurigo lombaire & France & Besnoit (1899) \\
\hline 20 & Prurigo lumbar & Spain & Yam (2003) \\
\hline 21 & Reiberkrankheit & Germany & Beck et al. (1964) \\
\hline 22 & Reiber-Uebel & Germany & von Richthofen (1827) \\
\hline 23 & Rickets & England & Beck et al. (1964) \\
\hline 24 & Rida & Iceland & Palsson (1979) \\
\hline 25 & Rub/Rubbers & England & Beck et al. (1964) \\
\hline 26 & Rubbing disease & England & Parry (1983) \\
\hline 27 & Ruppe & Germany & Frank (1820) \\
\hline 28 & Scabies dorsalis & Germany & Hörnlimann et al. (2001) \\
\hline 29 & Schrucken/Schru(c)kigsein & Germany & Frank (1820) \\
\hline 30 & Scratchie & Scotland & Liberski and Jaskólski (2002) \\
\hline 31 & Shakings & England & Beck et al. (1964) \\
\hline 32 & Shrewcroft & England & Liberski and Jaskólski (2002) \\
\hline 33 & Shrugginess & England & Parry (1983) \\
\hline 34 & Spruckigkeit & Germany & Schneider et al. (2008) \\
\hline 35 & Tempermänner & Germany & Erdt (1861) \\
\hline 36 & Trab(en)/Traberkrankheit & Germany & Beck et al. (1964) \\
\hline 37 & Trotting disease & England & Schneider et al. (2008) \\
\hline 38 & Trze sawka & Poland & Liberski and Jaskólski (2002) \\
\hline 39 & Wetzkrankheit & Germany & May (1868) \\
\hline 40 & Yeukie pine & Scotland & Healy et al. (2003) \\
\hline 41 & Zitterkrankheit & Germany & May (1868) \\
\hline
\end{tabular}

The description of literature is that scrapie was firstly born in Europe in the 18th century but until now the presence of scrapie in Europe is a dangerous sign for all over the world due to the threat of its spreading (Fig. 1) from England to all over the world (Detwiler and Baylis, 2003). The evidence of the scrapie in the European Union and the nearby regions from the day first till 2016 (EFSA, 2017) were as follows.

In 1987, 442 animals infected with scrapie were reported in England. In 1992, the number of animals infected with scrapie were reported as 37301. This number was reported as 1123 in 2002 and 610 animals in 2013, after that there were no reports of animals infected with scrapie. In Ireland, 15 animals were reported in 1990, in 2002, a total of 334 animals were reported, and in 2017, the disease showed peak time. Scrapie disease in France was first published in 1993, in 2002, 240 patients were reported. The first case was reported in Germany in 1991, the number of animals 
reported in 2002 were 7, while in 2001, 125 animals were published (EFSA, 2017). The first case of scrapie in Spain was reported in 1987, and in 2001, it was observed that the number of infected animals had been increased (Acín et al., 2004). Spain has started to work on the genotypic characterization of various races in this sense, to develop different strategies for each race and to prepare the laws governing these programs (Ugarte and Gabina, 2004). The first case of scrapie in Greece was settled in the north of the country in 1986, and the second case was diagnosed in 1997, the latter case was diagnosed after 11 years. The second case was seen near the region where the first case was observed, which was the evidence that the implemented eradication program is inadequate (Leontides et al., 2000). In 2001, there were 18 cases reported in Greece. According to the eradication program in Greece, the herds with the disease were massacred (Billinis et al., 2004). As a result of the breeding policies observed in Europe, the number of scrapie cases has decreased since 2009 (EFSA, 2014). In sheep, 933 scrapie cases were reported in the EU in 2017, which is an increase of $36.2 \%$ compared with 2016 (EFSA, 2018). In Figure 2, Cosseddu showed us the presence of scrapie in all over the world in 2007.

\section{Resistance and susceptibility}

Sheep can be resistant and susceptible to the disease and the majority of susceptible sheep are in European countries. Every one of these discernments lead to the European Union (EU) keeping on developing breeding projects focused at developing the frequency of safe alleles in breeds from all member-states. These European programs are established on five groups of genotypes, from extremely resistant to extremely sensitive, whose alleles ARR and VRQ are considered highly resistant and susceptible to scrapie, respectively (Hunter, 1997).

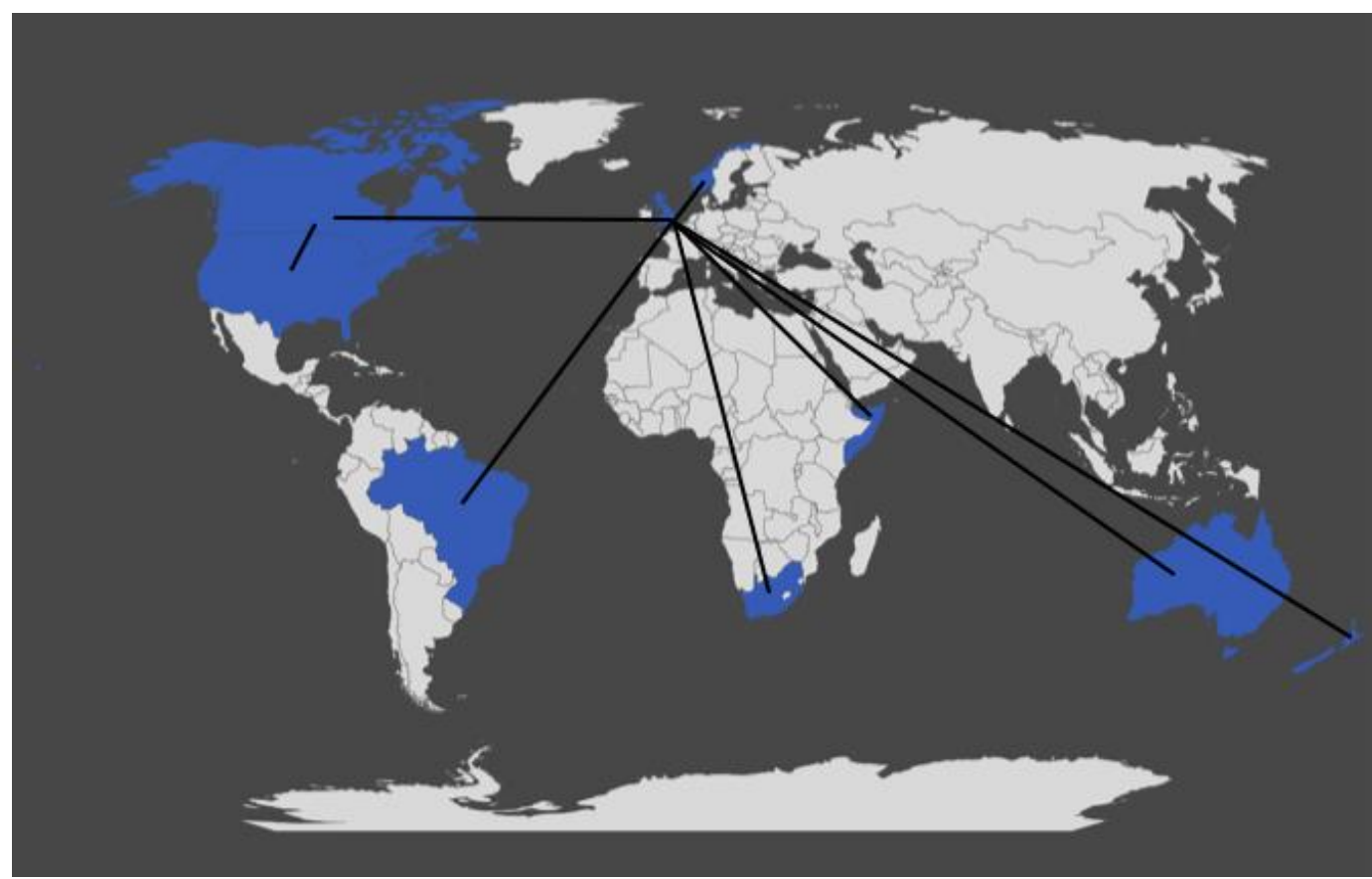

Figure 1. Spread of scrapie from England to the major parts of the world in 2003 (Detwiler and Baylis, 2003) 


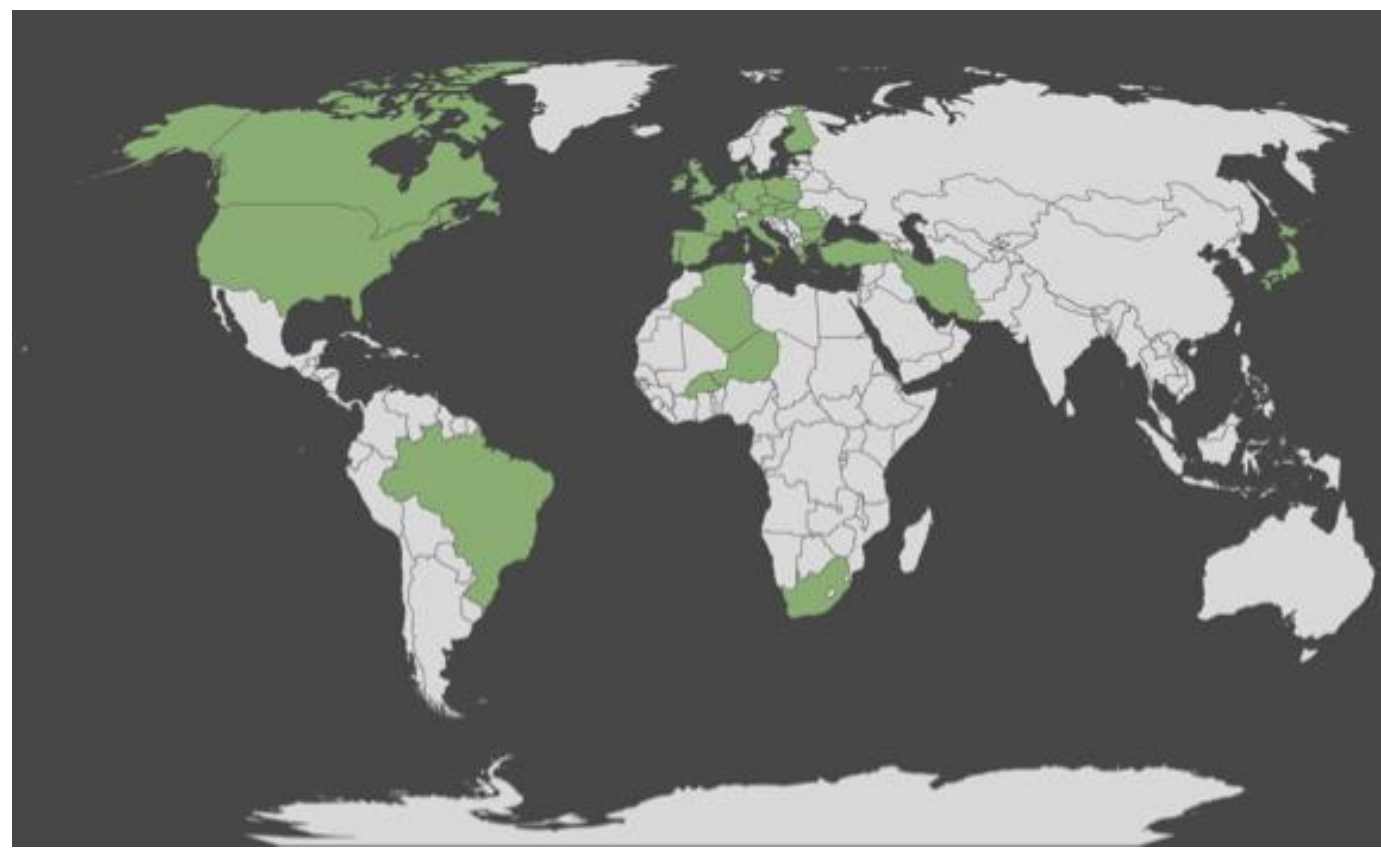

Figure 2. Scrapie distribution in all over the world in 2007 (Cosseddu et al., 2007)

As it is clear that polymorphisms at residues 136, 154, and 171 are associated with susceptibility to both, experimental and natural scrapie (Hunter, 1997). In sheep, breeding projects have been set up in a few European nations to expand the ARR allele as much as possible. To evade the negative outcomes of scrapie-safe alleles, it is indispensable to know their populace recurrence. Some programs are still working on the frequencies to get rid of the susceptible alleles. In Table 4 we can see the genotype groups and the intensity of risk.

\section{Prions and scrapie}

Scrapie is a protein misfolding where the normal prp misfolds into abnormal prp that is extremely resistant to enzymatic breakdown within the cell and accumulates, ultimately leading to neurodegeneration. The disease is experimentally transmissible to cattle, goats, and laboratory animals via oral, parenteral, and intracerebral routes using homogenates of a brain or lymphoid tissues from infected animals (Pattison et al., 1961). Squirrel monkey was infected by feeding infected tissues and many other species like rats, mice, chimpanzees and many others were infected as well (de Mouton, 2007). The mode of transmission from ewe to lamb or between adults in field environments is not clear. However, oral exposure to fetal membranes or to pastures grazed by infected animals has been implicated as a possible route of vertical and horizontal transmission (Brotherston et al., 1968). Susceptibility to ovine scrapie is controlled by a combination of host genetics. During the course of a prion disease, a largely protease-resistant aggregated form of prp designated abnormal prp, accumulates mainly in the brain, and maybe the main or only constituent of the prion but in some species little or no signs of accumulation other than brain were found (de Mouton, 2007). The alteration of the normal prp into the abnormal prp is the vital route of transmission and pathogenesis of the prion disease in sheep. Transgenic studies say that abnormal prp acts as a template 
on which normal prp is refolded into a nascent abnormal prp molecule through a process facilitated by another protein. Because no differences in the primary sequence were found between normal prp and abnormal prp, the two species are believed to differ only in their conformation. After normal prp is synthesized in the endoplasmic reticulum, it transits through the Golgi to the cell surface where it is bound by a glycophosphatidyl inositol (GPI)-anchor. At or near the cell surface, normal prp is either metabolized or converted into abnormal prp (Benke et al., 2007). Normal prp seems to re-enter cells through caveolae-like domains (CLDs), a subcellular compartment defined biochemically by membranes rich in cholesterol and glycosphingolipids; this compartment also contains many GPI-anchored proteins. Polymorphisms in the prion protein gene $(P R N P)$ determine the amino acid sequence of the host's prion protein and play a major role in relative susceptibility or resistance to classical scrapie. Prion protein (PRNP) gene is well known for affecting mammal transmissible spongiform encephalopathies (TSE) and is also reported to regulate phenotypic traits (e.g., growth traits) in healthy ruminants. As the vital control gene of fatal prion diseases or transmissible spongiform encephalopathies (TSE), the prion protein (PRNP) gene will always be a focus of ovine research (Houston et al., 2015; Stepanek and Horin, 2017). The PRNP gene encodes the prion protein (PrP), which plays a major role in the disease process (Goldmann, 2008; Houston et al., 2015). In sheep, amino acid polymorphisms at many positions $(89,94,101,112,127,128,132$, $134,135,136,137,138,141,143,145,146,149,151,152,154,157,159,160,163$, $164,167,168,169,171,172,174,175,176,180,183,184,185,189,193,195,196$, 199, 211, 213, 220, 224, 241) have been described (Oner et al., 2011), but the polymorphisms at codons 136, 154 and 171 have been demonstrated to be of major importance, as they modulate the susceptibility/resistance of sheep for scrapie (Clouscard et al., 1995; Hunter et al., 1996).

These polymorphisms are Alanine (A), Valine (V) or Threonine (T) at codon 136, Arginine (R) or Histidine (H) at codon 154 and Glutamine (Q), R, H or Lysine (K) at codon 171. The five most common haplotypes are ARR, ARQ, AHQ, ARH, and VRQ. New haplotypes (TRQ, ARK, VRR, AHR, VHQ, and TRR) have been reported so far. Haplotype alleles encoding three other forms of $\operatorname{PrP}$ (ARQ, AHQ, and ARH, where $\mathrm{H}$ is histidine) have intermediate associations with classical scrapie disease progression following exposure to the transmissible agent (Goldmann, 2008). Over 30 SNPs already showed that the ovine prion gene (PrP) shows an unusually high level of genetic variation (Goldmann et al., 2005). The ovine PRNP, mapped to chromosome 13, is a highly polymorphic gene consisting of three exons, among which only the third is translated (Lee et al., 1998). Single nucleotide polymorphisms (SNPs) leading to amino acid change in PrP were observed in over 20 codons, but most of them are rare and unrelated to disease development (Goldmann et al., 2005). It was established that polymorphisms A136V (Alanine, GCC $\rightarrow$ GTC, Valine), R154H (arginine, CGT $\rightarrow$ CAT, histidine) and Q171R (glutamine, CAG $\rightarrow$ CGG, arginine) are associated with susceptibility or resistance to scrapie (Baylis et al., 2004). Additionally, some studies reported another polymorphic variant coding for histidine at codon 171 , but it is very rare (Acín et al., 2004). The combination of these polymorphisms results in the creation of 3-locus haplotypes and diploid genotypes, among which A136R154Q171 (hereafter ARQ) haplotype and AA136RR154QQ171 (hereafter ARQ/ARQ) genotype are thought to be wild-type variants. With the help of Table 4, we can see the severity or intensity of genotypes. 
Table 4. According to the intensity of risk, scientists has classified the risk groups (Cosseddu et al., 2007)

\begin{tabular}{|c|c|c|}
\hline Risk class & Genotype & Risk intensity \\
\hline 1 & ARR/ARR & Sheep are highly resistant to scrapie \\
\hline 2 & $\begin{array}{l}\text { ARR/AHQ } \\
\text { ARR/ARH } \\
\text { ARR/ARQ }\end{array}$ & $\begin{array}{l}\text { Sheep are resistant to scrapie, thus require particular } \\
\text { attention in breeding programs }\end{array}$ \\
\hline 3 & $\begin{array}{l}\text { ARQ/ARH } \\
\text { ARQ/AHQ } \\
\text { AHQ/AHQ } \\
\text { ARH/ARH } \\
\text { AHQ/ARH } \\
\text { ARQ/ARQ }\end{array}$ & $\begin{array}{l}\text { Sheep with low genetic resistance to scrapie. Their use in } \\
\text { breeding programs must be avoided }\end{array}$ \\
\hline 4 & AHQ/ARH & Sheep are sensitive to scrapie \\
\hline 5 & $\begin{array}{l}\text { AHQ/VRQ } \\
\text { ARH/VRQ } \\
\text { ARQ/VRQ } \\
\text { VRQ/VRQ }\end{array}$ & $\begin{array}{l}\text { Sheep are highly sensitive to scrapie, thus must be } \\
\text { castrated or culled }\end{array}$ \\
\hline
\end{tabular}

The rapid dissemination of scrapie over the previous limited years led to the development of a specific eradication program, based on the polymorphisms within the prion protein gene $(P R N P)$. The current approach encourages the selection of animals carrying the resistant ARR/ARR genotype, while other genotypes are considered not preferable. Although the strategy seems to be working quite well, farmers are concerned whether this will affect sheep productivity and subsequently decrease net profits. Current scrapie eradication program includes genotyping and subsequent selection of animals on the ARR/ARR genotype.

\section{Genotype and haplotype}

Observing the development of PRNP genotype and haplotype is a powerful pointer of choice weight, which is evaluated in reference class creatures alongside ages so as to dodge predisposition, while the advancement in the common populace is assessed depending on scientific models. In countries where the scrapie incidence was statistically significant (see Tables 5 and 6), such as from Romania (Lacaune) the genotype frequencies are (ARR/ARR: 15.1) and (ARQ/VRQ: 12.6) (Otelea et al., 2011); from Romania (Turcana) (ARR/ARR: 14.64) and (ARQ/VRQ: 12.2) (Coşier et al., 2011); from Finland (Finnish Landrace) (ARR/ARR: 1.3) and (ARQ/VRQ: 10.3) (Hautaniemi et al., 2012); from Italy (Biellese rams) (ARQ/VRQ: 1.4) and (ARQ/VRQ: 9.9) (Acutis et al., 2004); from Slovakia (Orava) (ARR/ARR; 10.9) and (ARQ/VRQ: 9.0) (Tkáčiková et al., 2003); from Slovakia (Valachian) (ARR/ARR; 10.9) and (ARQ/VRQ: 9.0) (Tkáčiková et al., 2003); rom Slovakia (Spiš) (ARR/ARR; 10.8) and (ARQ/VRQ; 8.9) (Tkáčiková et al., 
2003); from Germany (Texel) (ARR/ARR; 11.7) and (ARQ/VRQ; 7.8) (Kutzer et al., 2002); from Greece (Greek Dairy Breed) (ARR/ARR; 2.2) and (ARQ/VRQ; 5.4) (Boukouvala et al., 2018a); from Spain (Rasa Aragonesa) (ARR/ARR; 2.0) and (ARQ/VRQ; 5.0) (Acín et al., 2004); from Poland (Pomorska) (ARR/ARR; 13.3) and (ARQ/VRQ; 3.3) (Lühken et al., 2008); from Poland (Pomorska) (ARR/ARR; 13.3) and (ARQ/VRQ; 3.3) (Acín et al., 2004); from Spain (Roya Bilbilitana) (ARR/ARR; 2.0) and (ARQ/VRQ; 3.0) (Acín et al., 2004); from Poland (Kaminieniecka) (ARR/ARR; 35.3) and (ARQ/VRQ; 2.9) (Szkudlarek-Kowalczyk et al., 2010); from Germany (Nolana) (ARR/ARR; 32.4) and (ARQ/VRQ; 2.8) (Kutzer et al., 2002); from Turkey (Imroz) (ARR/ARR; 29.9) and (ARQ/VRQ; 2.7) (Oner et al., 2011); from Brazil (Santa Ines sheep) (ARR/ARR; 7.4) and (ARQ/VRQ; 2.2) (Andrade et al., 2018); from Greece (Crossbred) (ARR/ARR; 7.3) and (ARQ/VRQ; 1.9) (Kioutsioukis et al., 2018); from Greece (Chios crossbred) (ARR/ARR; 2.7) and (ARQ/VRQ; 1.6) (Kioutsioukis et al., 2018); from Brazil (Dorset sheep) (ARR/ARR; 11.6) and (ARQ/VRQ; 1.5) (Andrade et al., 2018); from Iran (local sheep) (ARR/ARR; 38) and (ARQ/VRQ; 1.2) (Karami et al., 2011); from Greece (chios) (ARR/ARR; 1.2) and (ARQ/VRQ; 1.2) (Kioutsioukis et al., 2018); from Poland (Ile de France) (ARR/ARR; 72.0) and (ARQ/VRQ; 1.1) (Wisniewska and Mroczkowski, 2009); from Poland (Polish Merino) (ARR/ARR; 7.1) and (ARQ/VRQ; 1.0) (Wiśniewska et al., 2006); from Turkey (Kivircik) (ARR/ARR; 1.41) and (ARQ/VRQ; 0.7) (Oner et al., 2011); from Greece (Chios) (ARR/ARR; 0.4) and (ARQ/VRQ; 0.5) (Psifidi et al., 2011); from England (15 scrapie affected flocks) (ARR/ARR; 14.8) and (ARQ/VRQ; 0.2) (Tongue et al., 2004); from Pakistan (Kajli) (ARR/ARR; 1.9) (Babar et al., 2009); from China (Gansu Alpine Merino sheep) (ARR/ARR; 20.7) (Liu et al., 2017); from the Czech Republic (Charollais) (ARR/ARR; 61.5) (Stepanek and Horin, 2017). Breeding programs planned to increase the RR171 genotype in sheep populations and eliminate affected animals, to considerably decrease the number of classical scrapie cases in America and in the European Union (Greenlee, 2019). This is cleared that these genotypes and haplotypes are the backbone in the resistance and susceptibility of scrapie, which can be low or high. From Table 5 we can clearly say that, in Romania, Finland, Italy, Slovakia, Germany, Greece, Spain, Germany, Brazil, Iran, Poland, Turkey, Greece, England, Portugal and Hungary sheep are highly sensitive to scrapie, therefore must be eliminated or separated and in countries like Pakistan and China resistance to scrapie was observed.

The writers propose that arginine/glutamine replacement in the 171st position of the sheep PRNP might have affected the scrapie incubation period. In some countries the haplotype is very significant, that can be seen in Table 6, like the ARR in German Blackheaded Mutton; 87.0 which is the highest ARR frequency recorded and the highest VRQ frequency is recorded in Lacunae from Romania 18.9. The countries where the VRQ frequencies are found are Romania, Poland, Greece, Germany, Italy, Slovakia, Czech Republic, Finland, Germany, Austria, Spain, Turkey, Finland, Iran, Hungary; these are highly sensitive to scrapie, thus sheep must be eliminated and breeding programs must be introduced.

From these two tables and from the graphical presentation in Figures 3 and 4, we can see the clear difference between the countries where the scrapie is present, or the chance of scrapie is severe. The countries like China and Pakistan must take some important steps like proper breeding programs, before doing meat or any kind of trade associated with sheep with countries like Romania, Greece and the other countries found susceptible to scrapie. 
Table 5. Genotypic frequencies of PRNP gene at codon 131, 154 and 171 in various breeds of sheep in major parts of the world

\begin{tabular}{|c|c|c|c|c|c|c|c|c|c|c|c|c|c|}
\hline$\#$ & Country & Breed & $\mathbf{N}$ & $\begin{array}{l}\text { ARR/ } \\
\text { ARR }\end{array}$ & $\begin{array}{l}\text { ARR/ } \\
\text { ARQ }\end{array}$ & $\begin{array}{l}\text { ARQ/ } \\
\text { ARQ }\end{array}$ & $\begin{array}{l}\text { ARR/ } \\
\text { AHQ }\end{array}$ & $\begin{array}{l}\text { ARQ/ } \\
\text { AHQ }\end{array}$ & $\begin{array}{l}\text { AHQ/ } \\
\text { AHQ }\end{array}$ & $\begin{array}{l}\text { ARR/ } \\
\text { VRQ }\end{array}$ & $\begin{array}{l}\text { VRQ/ } \\
\text { VRQ }\end{array}$ & $\begin{array}{l}\text { ARQ/ } \\
\text { VRQ }\end{array}$ & Reference \\
\hline 1 & Romania & Lacaune & 159 & 15.1 & 33.3 & 20.1 & 5.0 & 5.7 & & 6.3 & & 12.6 & $\begin{array}{l}\text { Otelea et al. } \\
(2011)\end{array}$ \\
\hline 2 & Romania & Turcana & 123 & 14.64 & 32.52 & 28.46 & 0.81 & 1.63 & & 5.69 & & 12.2 & $\begin{array}{l}\text { Coşier et al. } \\
\text { (2011) }\end{array}$ \\
\hline 3 & Finland & Finnish Landrace & 232 & 1.3 & 15.9 & 68.8 & & 0.4 & & & 0.4 & 10.3 & $\begin{array}{l}\text { Hautaniemi et } \\
\text { al. (2012) }\end{array}$ \\
\hline 4 & Italy & Biellese rams & 1207 & 1.4 & 11.4 & 56.3 & 0.7 & 5.5 & 0.2 & 1.2 & 0.7 & 9.9 & $\begin{array}{c}\text { Acutis et al. } \\
\text { (2004) }\end{array}$ \\
\hline 5 & Slovakia & Orava & 366 & 10.9 & 45.4 & 19.4 & 5.7 & 4.9 & 0.8 & 3.6 & 0.3 & 9.0 & $\begin{array}{c}\text { Tkáčiková et al. } \\
\text { (2003) }\end{array}$ \\
\hline 6 & Slovakia & Valachian & 735 & 10.9 & 45.2 & 19.3 & 5.7 & 4.9 & 0.7 & 3.5 & 0.3 & 9.0 & $\begin{array}{c}\text { Tkáčiková et al. } \\
\text { (2003) }\end{array}$ \\
\hline 7 & Slovakia & Spiš & 369 & 10.8 & 54.0 & 19.2 & 0.5 & 4.9 & 0.5 & 3.5 & 0.3 & 8.9 & \begin{tabular}{|c|} 
Tkáčiková et al. \\
$(2003)$
\end{tabular} \\
\hline 8 & Germany & Texel & 231 & 11.7 & 19.5 & 25.1 & 0.4 & 2.2 & & 6.5 & 0.4 & 7.8 & $\begin{array}{c}\text { Kutzer et al. } \\
(2002)\end{array}$ \\
\hline 9 & Greece & Greek Dairy Breed & 4382 & 2.2 & 24.2 & 32.4 & & 12.5 & 2.0 & 1.23 & 0.3 & 5.4 & $\begin{array}{c}\text { Boukouvala et } \\
\text { al. (2018b) }\end{array}$ \\
\hline 10 & Spain & Rasa Aragonesa & 296 & 2.0 & 21.0 & 51.0 & 2.0 & 6.0 & 0.0 & 0.0 & & 5.0 & $\begin{array}{c}\text { Acín et al. } \\
\text { (2004) }\end{array}$ \\
\hline 11 & Poland & Pomorska & 30 & 13.3 & 36.7 & 16.7 & 6.7 & 6.7 & & 3.3 & 3.3 & 3.3 & $\begin{array}{c}\text { Lühken et al. } \\
\text { (2008) }\end{array}$ \\
\hline 12 & Spain & Ojinegra & 182 & 2.0 & 21 & 56 & 0.0 & 1 & 0.0 & 1.0 & & 3.0 & $\begin{array}{l}\text { Acín et al. } \\
(2004)\end{array}$ \\
\hline 13 & Spain & Roya Bilbilitana & 96 & 2.0 & 34 & 53 & 1.0 & 0 & 0.0 & 1.0 & & 3.0 & $\begin{array}{l}\text { Acín et al. } \\
\text { (2004) }\end{array}$ \\
\hline 14 & Poland & Kaminieniecka & 102 & 35.3 & 33.3 & 2.9 & & & & 6.9 & & 2.9 & $\begin{array}{l}\text { Szkudlarek- } \\
\text { Kowalczyk et } \\
\text { al. (2010) }\end{array}$ \\
\hline 15 & Germany & Nolana & 71 & 32.4 & 33.8 & 18.3 & & & & 4.2 & & 2.8 & $\begin{array}{c}\text { Kutzer et al. } \\
(2002)\end{array}$ \\
\hline 16 & Turkey & Imroz & 147 & 29.9 & 33.3 & 19.0 & 6.1 & 5.4 & & & 0.7 & 2.7 & $\begin{array}{c}\text { Oner et al. } \\
(2011)\end{array}$ \\
\hline 17 & Brazil & Santa Ines sheep & 94 & 7.4 & 21.3 & 47.8 & & 17 & & 1.1 & & 2.2 & $\begin{array}{c}\text { Andrade et al. } \\
\text { (2018) }\end{array}$ \\
\hline
\end{tabular}

APPLIED ECOLOGY AND ENVIRONMENTAL RESEARCH 18(4):5149-5173.

http://www.aloki.hu • ISSN 15891623 (Print) • ISSN 17850037 (Online)

DOI: http://dx.doi.org/10.15666/aeer/1804_51495173

○ 2020, ALÖKI Kft., Budapest, Hungary 


\begin{tabular}{|c|c|c|c|c|c|c|c|c|c|c|c|c|c|}
\hline$\#$ & Country & Breed & $\mathbf{N}$ & $\begin{array}{l}\text { ARR/ } \\
\text { ARR }\end{array}$ & $\begin{array}{l}\text { ARR/ } \\
\text { ARQ }\end{array}$ & $\begin{array}{l}\text { ARQ/ } \\
\text { ARQ }\end{array}$ & $\begin{array}{l}\text { ARR/ } \\
\text { AHQ }\end{array}$ & $\begin{array}{l}\text { ARQ/ } \\
\text { AHQ }\end{array}$ & $\begin{array}{l}\text { AHQ/ } \\
\text { AHQ }\end{array}$ & $\begin{array}{l}\text { ARR/ } \\
\text { VRQ }\end{array}$ & $\begin{array}{l}\text { VRQ/ } \\
\text { VRQ }\end{array}$ & $\begin{array}{l}\text { ARQ/ } \\
\text { VRQ }\end{array}$ & Reference \\
\hline 18 & Greece & Crossbred & 483 & 7.3 & 28.2 & 31.5 & 5.6 & 12.7 & 1.0 & 0.4 & 0.00 & 1.9 & $\begin{array}{c}\text { Kioutsioukis al. } \\
\text { (2018) }\end{array}$ \\
\hline 19 & Greece & Chios crossbred & 633 & 2.7 & 18.9 & 40.8 & 2.0 & 9.9 & 0.8 & 0.6 & 0.3 & 1.6 & $\begin{array}{l}\text { Kioutsioukis et } \\
\text { al. (2018) }\end{array}$ \\
\hline 20 & Brazil & Dorset sheep & 69 & 11.6 & 43.5 & 39.1 & & & & 4.3 & & 1.5 & $\begin{array}{l}\text { Andrade et al. } \\
\quad(2018)\end{array}$ \\
\hline 21 & Iran & Local sheeps & 250 & & 38 & 43.2 & & & & & & 1.2 & $\begin{array}{l}\text { Karami et al. } \\
(2011)\end{array}$ \\
\hline 22 & Greece & chios & 340 & 1.2 & 13.2 & 52.9 & 2.1 & 7.1 & 0.6 & 0.3 & 0.00 & 1.2 & $\begin{array}{l}\text { Kioutsioukis et } \\
\text { al. (2018) }\end{array}$ \\
\hline 23 & Poland & Ile de France & 93 & 72.0 & 6.5 & & & & & 17.2 & 3.2 & 1.1 & $\begin{array}{l}\text { Wisniewska and } \\
\text { Mroczkowski } \\
\text { (2009) }\end{array}$ \\
\hline 24 & Poland & Polish Merino & 98 & 7.1 & 54.1 & 35.7 & & & & 2.0 & & 1.0 & $\begin{array}{c}\text { Wiśniewska et } \\
\text { al. (2006) }\end{array}$ \\
\hline 25 & Turkey & Kivircik & 142 & 1.41 & 24.65 & 30.28 & 1.41 & 7.75 & & & & 0.7 & $\begin{array}{l}\text { One et al. } \\
\text { (2011) }\end{array}$ \\
\hline 26 & Greece & Chios & 1013 & 0.4 & 11.4 & 56.0 & 0.5 & 15.0 & 0.1 & & & 0.5 & $\begin{array}{l}\text { Psifidi et al. } \\
\quad(2011)\end{array}$ \\
\hline 27 & England & 15 scrapie affected flocks & 3732 & 14.8 & 30.7 & 15.7 & 7.8 & 8.2 & 1.5 & 7.6 & 0.8 & 0.2 & $\begin{array}{l}\text { Tongue et al. } \\
\text { (2004) }\end{array}$ \\
\hline 28 & Portugal & Merino Branco & 62 & 0.194 & 0.387 & 0.306 & 0.065 & 0.016 & 0.00 & 0.016 & & 0.00 & $\begin{array}{l}\text { Mesquita et al. } \\
\text { (2010) }\end{array}$ \\
\hline 29 & Portugal & Saloia & 52 & 0.096 & 0.231 & 0.442 & 0.038 & 0.135 & 0.00 & 0.019 & & 0.019 & $\begin{array}{l}\text { Mesquita et al. } \\
\quad(2010)\end{array}$ \\
\hline 30 & Portugal & Serra da Estrela & 69 & 0.174 & 0.420 & 0.304 & 0.014 & 0.014 & 0.00 & 0.014 & & 0.029 & $\begin{array}{l}\text { Mesquita et al. } \\
\quad(2010)\end{array}$ \\
\hline 31 & Portugal & $\begin{array}{c}\text { Bordaleira entre Douro e } \\
\text { Minho }\end{array}$ & 64 & 0.078 & 0.250 & 0.469 & 0.047 & 0.047 & 0.0 & 0.016 & & 0.047 & $\begin{array}{l}\text { Mesquita et al. } \\
\text { (2010) }\end{array}$ \\
\hline 32 & Portugal & Churra Badana & 58 & 0.052 & 0.345 & 0.517 & 0.017 & 0.052 & 0.0 & 0.00 & & 0.00 & $\begin{array}{l}\text { Mesquita et al. } \\
\text { (2010) }\end{array}$ \\
\hline 33 & Portugal & Churra Galega Mirandesa & 71 & 0.014 & 0.253 & 0.549 & 0.0 & 0.099 & 0.014 & 0.00 & & 0.056 & $\begin{array}{l}\text { Mesquita et al. } \\
\text { (2010) }\end{array}$ \\
\hline 34 & Portugal & Churra Mondegueira & 19 & 0.053 & 0.105 & 0.737 & 0.0 & 0.00 & 0.00 & 0.00 & & 0.00 & $\begin{array}{l}\text { Mesquita et al. } \\
\text { (2010) }\end{array}$ \\
\hline 35 & Portugal & Merino da Beira-Baixa & 65 & 0.092 & 0.231 & 0.523 & 0.0 & 0.31 & 0.00 & 0.031 & & 0.077 & $\begin{array}{l}\text { Mesquita et al. } \\
\text { (2010) }\end{array}$ \\
\hline
\end{tabular}

APPLIED ECOLOGY AND ENVIRONMENTAL RESEARCH 18(4):5149-5173.

http://www.aloki.hu • ISSN 15891623 (Print) • ISSN 17850037 (Online)

DOI: http://dx.doi.org/10.15666/aeer/1804_51495173

○ 2020, ALÖKI Kft., Budapest, Hungary 


\begin{tabular}{|c|c|c|c|c|c|c|c|c|c|c|c|c|c|}
\hline$\#$ & Country & Breed & $\mathbf{N}$ & $\begin{array}{l}\text { ARR/ } \\
\text { ARR }\end{array}$ & $\begin{array}{l}\text { ARR/ } \\
\text { ARQ }\end{array}$ & $\begin{array}{l}\text { ARQ/ } \\
\text { ARQ }\end{array}$ & $\begin{array}{l}\text { ARR/ } \\
\text { AHQ }\end{array}$ & $\begin{array}{l}\text { ARQ/ } \\
\text { AHQ }\end{array}$ & $\begin{array}{l}\text { AHQ/ } \\
\text { AHQ }\end{array}$ & $\begin{array}{l}\text { ARR/ } \\
\text { VRQ }\end{array}$ & $\begin{array}{l}\text { VRQ/ } \\
\text { VRQ }\end{array}$ & $\begin{array}{l}\text { ARQ/ } \\
\text { VRQ }\end{array}$ & Reference \\
\hline 36 & Hungary & Hungarian Tsigai & 392 & 0.27 & 0.4 & 0.2 & 0.06 & 0.02 & 0.0 & 0.02 & 0.06 & 0.06 & Mari (2016) \\
\hline 37 & Greece & Karagouniko & 100 & & 14.5 & 32 & & 6.0 & & & 7.9 & & $\begin{array}{l}\text { Billinis et al. } \\
\text { (2004) }\end{array}$ \\
\hline 38 & Austria & Carynthian sheep & 24 & 4.2 & 37.5 & 41.6 & & 4.2 & & & 4.2 & & $\begin{array}{c}\text { Sipos et al. } \\
(2002)\end{array}$ \\
\hline 39 & Turkey & Chios & 124 & 15.32 & 22.58 & 20.16 & 1.61 & 7.26 & 1.61 & & 0.8 & & $\begin{array}{c}\text { Oner et al. } \\
(2011)\end{array}$ \\
\hline 40 & Poland & Olkuska & 174 & 35.1 & 60.9 & 4.0 & & & & & & & $\begin{array}{c}\text { Kaczor et al. } \\
(2011)\end{array}$ \\
\hline 41 & Poland & Gorska & 31 & 12.9 & 51.6 & 22.6 & 3.2 & 9.7 & & & & & \begin{tabular}{|c|}
$\begin{array}{c}\text { Lühken et al. } \\
(2008)\end{array}$ \\
\end{tabular} \\
\hline 42 & Poland & Wrzosowka & 31 & 6.5 & 48.4 & 9.7 & 19.3 & 12.9 & 3.2 & & & & \begin{tabular}{|c|} 
Lühken, Lipsky \\
et al. (2008)
\end{tabular} \\
\hline 43 & Finland & Kainuu & 48 & & 16.7 & 83.3 & & & & & & & $\begin{array}{l}\text { Hautaniemi et } \\
\text { al. (2012) }\end{array}$ \\
\hline 44 & Germany & Suffolk & 87 & 14.9 & 20.7 & 54.0 & 1.1 & 1.1 & & & & & $\begin{array}{c}\text { Kutzer et al. } \\
(2002)\end{array}$ \\
\hline 45 & Pakistan & Awassi & 21 & & 4.8 & 92.2 & & & & & & & $\begin{array}{c}\text { Babar et al. } \\
(2009)\end{array}$ \\
\hline 46 & Pakistan & Buchi & 35 & & & 100 & & & & & & & $\begin{array}{l}\text { Babar et al. } \\
\text { (2009) }\end{array}$ \\
\hline 47 & Pakistan & Hissardale & 20 & 5 & & 70 & & & & & & & $\begin{array}{c}\text { Babaret al. } \\
\text { (2009) }\end{array}$ \\
\hline 48 & Pakistan & Kajli & 52 & 1.9 & 9.6 & 84.6 & & & & & & & $\begin{array}{c}\text { Babaret al. } \\
\text { (2009) }\end{array}$ \\
\hline 49 & Pakistan & Lohi & 50 & & 10 & 88 & & & & & & & $\begin{array}{c}\text { Babaret al. } \\
(2009)\end{array}$ \\
\hline 50 & Pakistan & Pak-Karakul & 19 & & 36.8 & 63.2 & & & & & & & $\begin{array}{c}\text { Babaret al. } \\
(2009)\end{array}$ \\
\hline 51 & Pakistan & Sipli & 41 & & & 65.9 & & & & & & & $\begin{array}{c}\text { Babaret al. } \\
\text { (2009) }\end{array}$ \\
\hline 52 & Pakistan & Thalli & 40 & & 25 & 100 & & & & & & & $\begin{array}{c}\text { Babaret al. } \\
(2009)\end{array}$ \\
\hline 53 & Pakistan & kachi & 30 & & & 100 & & & & & & & $\begin{array}{c}\text { Babaret al. } \\
(2009)\end{array}$ \\
\hline 54 & China & Gansu Alpine Merino sheep & 111 & 20.7 & 27 & 46 & & & & & & & Liu et al. (2017) \\
\hline
\end{tabular}

APPLIED ECOLOGY AND ENVIRONMENTAL RESEARCH 18(4):5149-5173.

http://www.aloki.hu • ISSN 15891623 (Print) • ISSN 17850037 (Online)

DOI: http://dx.doi.org/10.15666/aeer/1804_51495173

○ 2020, ALÖKI Kft., Budapest, Hungary 


\begin{tabular}{|c|c|c|c|c|c|c|c|c|c|c|c|c|c|}
\hline$\#$ & Country & Breed & $\mathbf{N}$ & $\begin{array}{l}\text { ARR/ } \\
\text { ARR }\end{array}$ & $\begin{array}{l}\text { ARR/ } \\
\text { ARQ }\end{array}$ & $\begin{array}{c}\text { ARQ/ } \\
\text { ARQ }\end{array}$ & $\begin{array}{l}\text { ARR/ } \\
\text { AHQ }\end{array}$ & $\begin{array}{l}\text { ARQ/ } \\
\text { AHQ }\end{array}$ & $\begin{array}{l}\text { AHQ/ } \\
\text { AHQ }\end{array}$ & $\begin{array}{l}\text { ARR/ } \\
\text { VRQ }\end{array}$ & $\begin{array}{l}\text { VRQ/ } \\
\text { VRQ }\end{array}$ & $\begin{array}{l}\text { ARQ/ } \\
\text { VRQ }\end{array}$ & Reference \\
\hline 55 & Algeria & Barbarine & 20 & & 20 & 40 & & & & & & & $\begin{array}{l}\text { Djaout et al. } \\
\text { (2018) }\end{array}$ \\
\hline 56 & Algeria & Berbere & 20 & 5 & 20 & 20 & & & & & & & $\begin{array}{c}\text { Djaout et al. } \\
(2018)\end{array}$ \\
\hline 57 & Algeria & Hamra & 27 & & 19 & 11 & & & & & & & $\begin{array}{c}\text { Djaout et al. } \\
(2018)\end{array}$ \\
\hline 58 & Algeria & Ouled Djellal & 35 & 8 & 17 & 11 & & & & & & & $\begin{array}{c}\text { Djaout et al. } \\
(2018)\end{array}$ \\
\hline 59 & Algeria & Rembi & 40 & 8 & 20 & 18 & & & & & & & $\begin{array}{c}\text { Djaout et al. } \\
(2018)\end{array}$ \\
\hline 60 & Algeria & Sidaou & 30 & & 3 & 23 & & & & & & & $\begin{array}{c}\text { Djaout et al. } \\
(2018)\end{array}$ \\
\hline 61 & Algeria & Taadmit & 10 & 20 & 10 & 10 & & & & & & & $\begin{array}{c}\text { Djaout et al. } \\
(2018)\end{array}$ \\
\hline 62 & Algeria & Tazegzawt & 31 & & 10 & 23 & & & & & & & $\begin{array}{c}\text { Djaout et al. } \\
(2018)\end{array}$ \\
\hline 63 & Czech Republic & Berrichone du Cher & 445 & 54.6 & & & & & & & & & $\begin{array}{l}\text { Stepanek and } \\
\text { Horin (2017) }\end{array}$ \\
\hline 64 & Czech Republic & Charollais & 3219 & 61.5 & & & & & & & & & $\begin{array}{l}\text { Stepanek and } \\
\text { Horin (2017) }\end{array}$ \\
\hline 65 & Czech Republic & East Friesian sheep & 1864 & 56.5 & & & & & & & & & $\begin{array}{l}\text { Stepanek and } \\
\text { Horin (2017) }\end{array}$ \\
\hline 66 & Czech Republic & German Blackheaded Mutton & 628 & 75.3 & & & & & & & & & $\begin{array}{l}\text { Stepanek and } \\
\text { Horin (2017) }\end{array}$ \\
\hline 67 & Czech Republic & Kent Romney) & 5995 & 38.0 & & & & & & & & & $\begin{array}{l}\text { Stepanek and } \\
\text { Horin (2017) }\end{array}$ \\
\hline 68 & Czech Republic & Merinolandschaf & 2057 & 33.1 & & & & & & & & & $\begin{array}{l}\text { Stepanek and } \\
\text { Horin (2017) }\end{array}$ \\
\hline 69 & Czech Republic & Oxford Down & 1044 & 59.5 & & & & & & & & & $\begin{array}{l}\text { Stepanek and } \\
\text { Horin (2017) }\end{array}$ \\
\hline 70 & Czech Republic & Romanov sheep & 3281 & 44.2 & & & & & & & & & $\begin{array}{l}\text { Stepanek and } \\
\text { Horin (2017) }\end{array}$ \\
\hline 71 & Czech Republic & Sumavka & 3358 & 23.1 & & & & & & & & & $\begin{array}{l}\text { Stepanek and } \\
\text { Horin (2017) }\end{array}$ \\
\hline 72 & Czech Republic & Suffolk & 12987 & 73.9 & & & & & & & & & $\begin{array}{l}\text { Stepanek and } \\
\text { Horin (2017) }\end{array}$ \\
\hline
\end{tabular}

APPLIED ECOLOGY AND ENVIRONMENTAL RESEARCH 18(4):5149-5173.

http://www.aloki.hu • ISSN 15891623 (Print) • ISSN 17850037 (Online)

DOI: http://dx.doi.org/10.15666/aeer/1804_51495173

๑ 2020, ALÖKI Kft., Budapest, Hungary 


\begin{tabular}{|c|c|c|c|c|c|c|c|c|c|c|c|c|c|}
\hline$\#$ & Country & Breed & $\mathbf{N}$ & $\begin{array}{l}\text { ARR/ } \\
\text { ARR }\end{array}$ & $\begin{array}{l}\text { ARR/ } \\
\text { ARQ }\end{array}$ & $\begin{array}{l}\text { ARQ/ } \\
\text { ARQ }\end{array}$ & $\begin{array}{l}\text { ARR/ } \\
\text { AHQ }\end{array}$ & $\begin{array}{l}\text { ARQ/ } \\
\text { AHQ }\end{array}$ & $\begin{array}{l}\text { AHQ/ } \\
\text { AHQ }\end{array}$ & $\begin{array}{l}\text { ARR/ } \\
\text { VRQ }\end{array}$ & $\begin{array}{l}\text { VRQ/ } \\
\text { VRQ }\end{array}$ & $\begin{array}{l}\text { ARQ/ } \\
\text { VRQ }\end{array}$ & Reference \\
\hline 73 & Czech Republic & Texel & 3142 & 72.7 & & & & & & & & & $\begin{array}{l}\text { Stepanek and } \\
\text { Horin (2017) }\end{array}$ \\
\hline 74 & Czech Republic & Valachian sheep & 1301 & 55.9 & & & & & & & & & $\begin{array}{l}\text { Stepanek and } \\
\text { Horin (2017) }\end{array}$ \\
\hline 75 & Czech Republic & Zwartbles & 1791 & 39.6 & & & & & & & & & $\begin{array}{l}\text { Stepanek and } \\
\text { Horin (2017) }\end{array}$ \\
\hline 76 & West Africa & Burkina-Sahel & 46 & & 6.5 & 80.4 & 2.2 & 10.9 & & & & & $\begin{array}{l}\text { Traoré et al. } \\
\text { (2012) }\end{array}$ \\
\hline 77 & West Africa & Djallonké & 50 & & & 86.0 & & 12.0 & 2.0 & & & & $\begin{array}{c}\text { Traoré et al. } \\
\text { (2012) }\end{array}$ \\
\hline 78 & West Africa & Mossi & 46 & & 6.5 & 76.1 & & 15.2 & 2.2 & & & & $\begin{array}{c}\text { Traoré et al. } \\
(2012)\end{array}$ \\
\hline 79 & West Africa & Touareg & 20 & & & 40.0 & & 55.0 & 5.0 & & & & $\begin{array}{c}\text { Traoré et al. } \\
(2012)\end{array}$ \\
\hline 80 & Finland & Grey race sheep & 48 & & 16.7 & 83.3 & & & & & & & $\begin{array}{l}\text { Hautaniemi et } \\
\text { al. (2012) }\end{array}$ \\
\hline 81 & Finland & Aland sheep & 56 & & 23.2 & 48.2 & & 19.6 & 8.9 & & & & $\begin{array}{l}\text { Hautaniemi et } \\
\text { al. (2012) }\end{array}$ \\
\hline 82 & Finland & Taxel & 71 & 1.4 & 31.0 & 33.8 & & 8.5 & & & & & $\begin{array}{l}\text { Hautaniemi et } \\
\text { al. (2012) }\end{array}$ \\
\hline 83 & America & Suffolk & 128 & 36.72 & 43.75 & 17.19 & & & & & & & $\begin{array}{l}\text { DeSilva et al. } \\
\text { (2003) }\end{array}$ \\
\hline 84 & America & Montadale & 47 & 17.02 & 23.40 & 19.15 & & & & & & & $\begin{array}{l}\text { DeSilva et al. } \\
\text { (2003) }\end{array}$ \\
\hline 85 & America & Hampshire & 91 & 20.88 & 52.75 & 26.37 & & & & & & & $\begin{array}{l}\text { DeSilva et al. } \\
\text { (2003) }\end{array}$ \\
\hline 86 & America & Dorset & 62 & 9.68 & 38.71 & 38.71 & & & & & & & $\begin{array}{c}\text { DeSilva et al. } \\
\text { (2003) }\end{array}$ \\
\hline 87 & Austria & Tyrolean mountain & 35 & 2.9 & 40.0 & 40.0 & 5.7 & 11.4 & & & & & $\begin{array}{c}\text { Sipos et al. } \\
(2002)\end{array}$ \\
\hline 88 & Austria & Forest sheep & 26 & 111.5 & 15.4 & 57.7 & & 11.5 & & & & & $\begin{array}{c}\text { Sipos et al. } \\
(2002)\end{array}$ \\
\hline 89 & Austria & Tyrolean stone sheep & 27 & & 29.6 & 40.7 & & 22.2 & & & & & $\begin{array}{c}\text { Sipos et al. } \\
(2002)\end{array}$ \\
\hline
\end{tabular}


Table 6. Haplotypic frequencies of PRNP gene at codons 136, 154 and 171: alanine $(A)$, arginine $(R)$, histidine $(H)$, glutamine $(Q)$ and valine (V) in various breeds of sheep in major parts of the world

\begin{tabular}{|c|c|c|c|c|c|c|c|c|}
\hline$\#$ & Country & Breed & $\mathbf{N}$ & ARR & ARQ & AHQ & VRQ & Reference \\
\hline 1 & Romania & Lacaune & 159 & 15.1 & 60.4 & 5.0 & 18.9 & Otelea et al. (2011) \\
\hline 2 & Poland & Ile de France & 93 & 83.8 & 3.8 & & 12.4 & Wisniewska and Mroczkowski (2009) \\
\hline 3 & Greece & Greek Dairy Breed & 4382 & 0.1 & 9.4 & 10 & 11.9 & Boukouvala et al. (2018b) \\
\hline 4 & Romania & Turcana & 123 & 34.1 & 53.7 & 1.2 & 8.9 & Coşier et al. (2011) \\
\hline 5 & Poland & Pomorska & 30 & 40.0 & 40.0 & 6.7 & 8.3 & Wiśniewska et al. (2006) \\
\hline 6 & Germany & Texel & 231 & 28.8 & 44.4 & 1.9 & 8.2 & Kutzer et al. (2002) \\
\hline 7 & Italy & Biellese rams & 2414 & 8.3 & 74.4 & 3.8 & 6.8 & Acutis et al. (2004) \\
\hline 8 & Slovakia & Valachian & 735 & 38.4 & 48.7 & 6.0 & 6.5 & Tkáčiková et al. (2003) \\
\hline 9 & Czech Republic & Valachian sheep & 1301 & 74.3 & & & 5.7 & Stepanek and Horin (2017) \\
\hline 10 & Finland & Finnish Landrace & 464 & 9.5 & 83.4 & 0.2 & 5.6 & Hautaniemiet al. (2012) \\
\hline 11 & Germany & Nolana & 71 & 52.8 & 36.6 & & 5.6 & Kutzer et al. (2002) \\
\hline 12 & Poland & Kaminieniecka & 102 & 63.2 & 21.6 & & 5.4 & Szkudlarek-Kowalczyk et al. (2010) \\
\hline 13 & Poland & Zelanienska & 31 & 46.8 & 43.6 & 4.8 & 4.8 & Lühken et al. (2008) \\
\hline 14 & Austria & Carynthian sheep & 24 & 23.0 & 64.6 & 4.2 & 4.2 & Sipos et al. (2002) \\
\hline 15 & Spain & Rasa Aragonesa & 296 & 15.0 & 70.9 & 4.8 & 2.9 & Acín et al. (2004) \\
\hline 16 & Spain & Roya Bilbilitana & 96 & 21.4 & 72.4 & 1 & 2.6 & Acín et al. (2004) \\
\hline 17 & Czech Republic & Romanov sheep & 3281 & 66.3 & & & 2.5 & Stepanek and Horin (2017) \\
\hline 18 & Turkey & Imroz & 147 & 50.0 & 40.1 & 5.8 & 2.4 & Oner et al. (2011) \\
\hline 19 & Greece & Chios crossbred & 633 & 15.0 & 63.4 & 7.7 & 1.7 & Kioutsioukis et al. (2018) \\
\hline 20 & Czech Republic & Zwartbles & 1791 & 63.7 & & & 1.6 & Stepanek and Horin (2017) \\
\hline 21 & Greece & Crossbred & 483 & 25.7 & 55.9 & 11.3 & 1.5 & Kioutsioukis et al. (2018) \\
\hline 22 & Poland & Polish Merino & 98 & 35.2 & 63.3 & & 1.5 & Wiśniewska et al. (2006) \\
\hline 23 & Finland & Taxel & 144 & 17.6 & 64.1 & 4.2 & 1.4 & Hautaniemiet al. (2012) \\
\hline 24 & Czech Republic & Charollais & 3219 & 79.6 & & & 1.3 & Stepanek and Horin (2017) \\
\hline 25 & Turkey & Kivircik & 142 & 30.64 & 39.52 & 6.83 & 0.8 & Oner et al. (2011) \\
\hline 26 & Greece & Chios & 340 & 10 & 71.5 & 5.8 & 0.7 & Kioutsioukis et al. (2018) \\
\hline
\end{tabular}




\begin{tabular}{|c|c|c|c|c|c|c|c|c|}
\hline$\#$ & Country & Breed & $\mathbf{N}$ & ARR & ARQ & AHQ & VRQ & Reference \\
\hline 27 & Iran & Local sheeps & 250 & & 67.8 & & 0.6 & Karami et al. (2011) \\
\hline 28 & Czech Republic & East Friesian sheep & 1864 & 76.1 & & & 0.5 & Stepanek and Horin (2017) \\
\hline 29 & Czech Republic & Sumavka & 3358 & 46.1 & & & 0.5 & Stepanek and Horin (2017) \\
\hline 30 & Greece & Chios & 1013 & 6.9 & 76.1 & 8.2 & 0.4 & Psifidi et al. (2011) \\
\hline 31 & Turkey & Chios & 124 & 17.25 & 56.69 & 5.63 & 0.4 & Oner et al. (2011) \\
\hline 32 & Czech Republic & Berrichone du Cher & 445 & 75.5 & & & 0.4 & Stepanek and Horin (2017) \\
\hline 33 & Spain & Ojinegra & 182 & 14.6 & 73.9 & 3 & 0.3 & Acín et al. (2004) \\
\hline 34 & Greece & Random breeds & 5815 & 47.7 & 44.9 & 3.9 & 0.3 & Boukouvala et al. (2018b) \\
\hline 35 & Czech Republic & Texel & 3142 & 85.9 & & & 0.2 & Stepanek and Horin (2017) \\
\hline 36 & Czech Republic & Suffolk & 12987 & 86.28 & & & 0.1 & Stepanek and Horin (2017) \\
\hline 37 & Czech Republic & Merinolandschaf & 2057 & 59.3 & & & 0.1 & Stepanek and Horin (2017) \\
\hline 38 & Czech Republic & Kent Romney) & 5995 & 63.5 & & & 0.1 & Stepanek and Horin (2017) \\
\hline 39 & Hungary & Hungarian Tsigai & 569 & 0.5 & 0.4 & 0.05 & 0.01 & Mari (2016) \\
\hline 40 & Czech Republic & German Blackheaded Mutton & 628 & 87.0 & & & 0.0 & Stepanek and Horin (2017) \\
\hline 41 & Czech Republic & Oxford Down & 1044 & 79.2 & & & 0.0 & Stepanek and Horin (2017) \\
\hline 42 & Finland & Grey race sheep & 96 & 8.3 & 91.7 & 0 & 0 & Hautaniemiet al. (2012) \\
\hline 43 & Finland & Aland sheep & 112 & 11.6 & 69.6 & 18.8 & 0 & Hautaniemiet al. (2012) \\
\hline 44 & Poland & Olkuska & 174 & 65.5 & 34.5 & & & Kaczor et al. (2011) \\
\hline 45 & Poland & Polish Mountain & 31 & 40.3 & 53.2 & 6.5 & & Wiśniewska et al. (2006) \\
\hline 46 & Poland & Wrzosowka & 31 & 41.9 & 38.7 & 19.4 & & Lühken et al. (2008) \\
\hline 47 & Finland & Kainuu & 48 & 8.3 & 91.7 & & & Hautaniemi et al. (2012) \\
\hline 48 & Greece & Karagouniko & 100 & 28.5 & 66.0 & 3.0 & & Billinis et al. (2004) \\
\hline 49 & Germany & Suffolk & 87 & 27.0 & 67.2 & 1.1 & & Kutzer et al. (2002) \\
\hline 50 & China & Xinjiang Sheeps & 222 & 9.0 & 75.2 & 2.3 & & Lan et al. (2006) \\
\hline 51 & Algeria & Barbarine & 20 & 15 & 65 & & & Djaout et al. (2018) \\
\hline 52 & Algeria & Berbere & 20 & 18 & 48 & 3 & & Djaout et al. (2018) \\
\hline 53 & Algeria & Hamra & 27 & 11 & 41 & 7 & & Djaout et al. (2018) \\
\hline 54 & Algeria & Ouled Djellal & 35 & 26 & 31 & 3 & & Djaout et al. (2018) \\
\hline
\end{tabular}




\begin{tabular}{|c|c|c|c|c|c|c|c|c|}
\hline$\#$ & Country & Breed & $\mathbf{N}$ & ARR & ARQ & AHQ & VRQ & Reference \\
\hline 55 & Algeria & Rembi & 40 & 24 & 43 & 3 & & Djaout et al. (2018) \\
\hline 56 & Algeria & Sidaou & 30 & 8 & 45 & 2 & & Djaout et al. (2018) \\
\hline 57 & Algeria & Taadmit & 10 & 30 & 30 & 10 & & Djaout et al. (2018) \\
\hline 58 & Algeria & Tazegzawt & 31 & 8 & 47 & 3 & & Djaout et al. (2018) \\
\hline 59 & Burkina Faso & Burkina-Sahel & 46 & 4.4 & 89.1 & 6.5 & & Traoré et al. (2012) \\
\hline 60 & Burkina Faso & Djallonké & 50 & & 92.0 & 8.0 & & Traoré et al. (2012) \\
\hline 61 & Burkina Faso & Mossi & 46 & 3.2 & 87.0 & 9.8 & & Traoré et al. (2012) \\
\hline 62 & Niger & Touareg & 20 & & 67.5 & 32.5 & & Traoré et al. (2012) \\
\hline 63 & Austria & Tyrolean mountain & 35 & 25.8 & 65.7 & 8.6 & & Sipos et al. (2002) \\
\hline 64 & Austria & Forest sheep & 26 & 19.2 & 71.2 & 5.8 & & Sipos et al. (2002) \\
\hline 65 & Austria & Tyrolean stone sheep & 27 & 14.8 & 70.3 & 11.1 & & Sipos et al. (2002) \\
\hline 66 & China & Lanzhou large-tailed sheep & 30 & 0 & 26 & 0 & & Lan et al. (2014) \\
\hline 67 & China & Mongol sheep & 30 & 0 & 26 & 0 & & Lan et al. (2014) \\
\hline 68 & China & Tan sheep & 30 & 0 & 25 & 0 & & Lan et al. (2014) \\
\hline 69 & China & Gaoyuan sheep & 30 & 0 & 32 & 0 & & Lan et al. (2014) \\
\hline 70 & China & Guide fur sheep & 30 & 0 & 28 & 0 & & Lan et al. (2014) \\
\hline 71 & China & Oula sheep & 30 & 0 & 30 & 0 & & Lan et al. (2014) \\
\hline 72 & China & Lowland sheep & 30 & 0 & 28 & 0 & & Lan et al. (2014) \\
\hline 73 & China & Sishui fur sheep & 30 & 0 & 21 & 0 & & Lan et al. (2014) \\
\hline 74 & China & Small-tailed Han sheep & 30 & 0 & 22 & 0 & & Lan et al. (2014) \\
\hline 75 & China & Hu sheep & 30 & 2 & 25 & 0 & & Lan et al. (2014) \\
\hline 76 & China & Tong sheep & 30 & 1 & 25 & 0 & & Lan et al. (2014) \\
\hline 77 & China & Duolang sheep & 30 & 1 & 27 & 0 & & Lan et al. (2014) \\
\hline 78 & China & Diqing sheep & 30 & 2 & 30 & 1 & & Lan et al. (2014) \\
\hline 79 & China & Tengchong sheep & 30 & 1 & 12 & 17 & & Lan et al. (2014) \\
\hline 80 & China & Zhaotong sheep & 30 & 1 & 7 & 22 & & Lan et al. (2014) \\
\hline 81 & China & Tibetan sheep & 30 & 3 & 27 & 0 & & Lan et al. (2014) \\
\hline
\end{tabular}

APPLIED ECOLOGY AND ENVIRONMENTAL RESEARCH 18(4):5149-5173.

http://www.aloki.hu • ISSN 15891623 (Print) • ISSN 17850037 (Online)

DOI: http://dx.doi.org/10.15666/aeer/1804_51495173

๑ 2020, ALÖKI Kft., Budapest, Hungary 


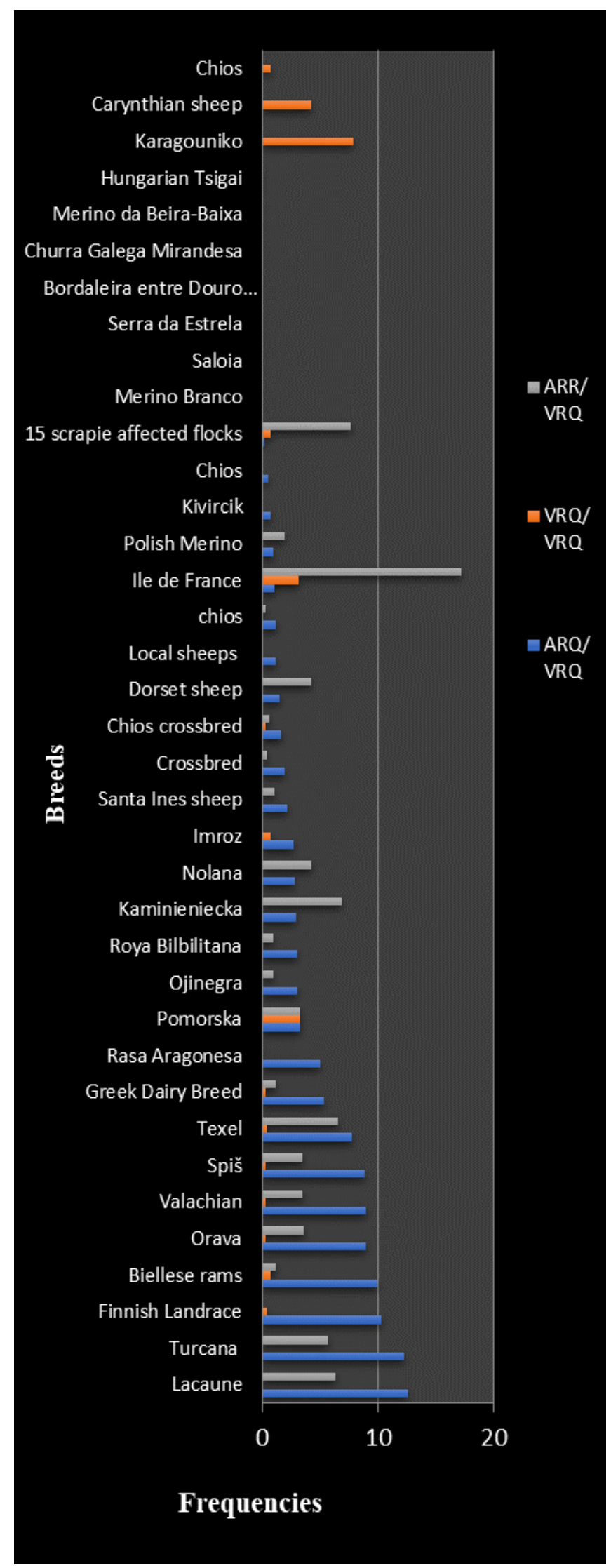

Figure 3. Genotype frequencies of PRNP gene at codons 136, 154 and 171. (Constructed from Table 5) 


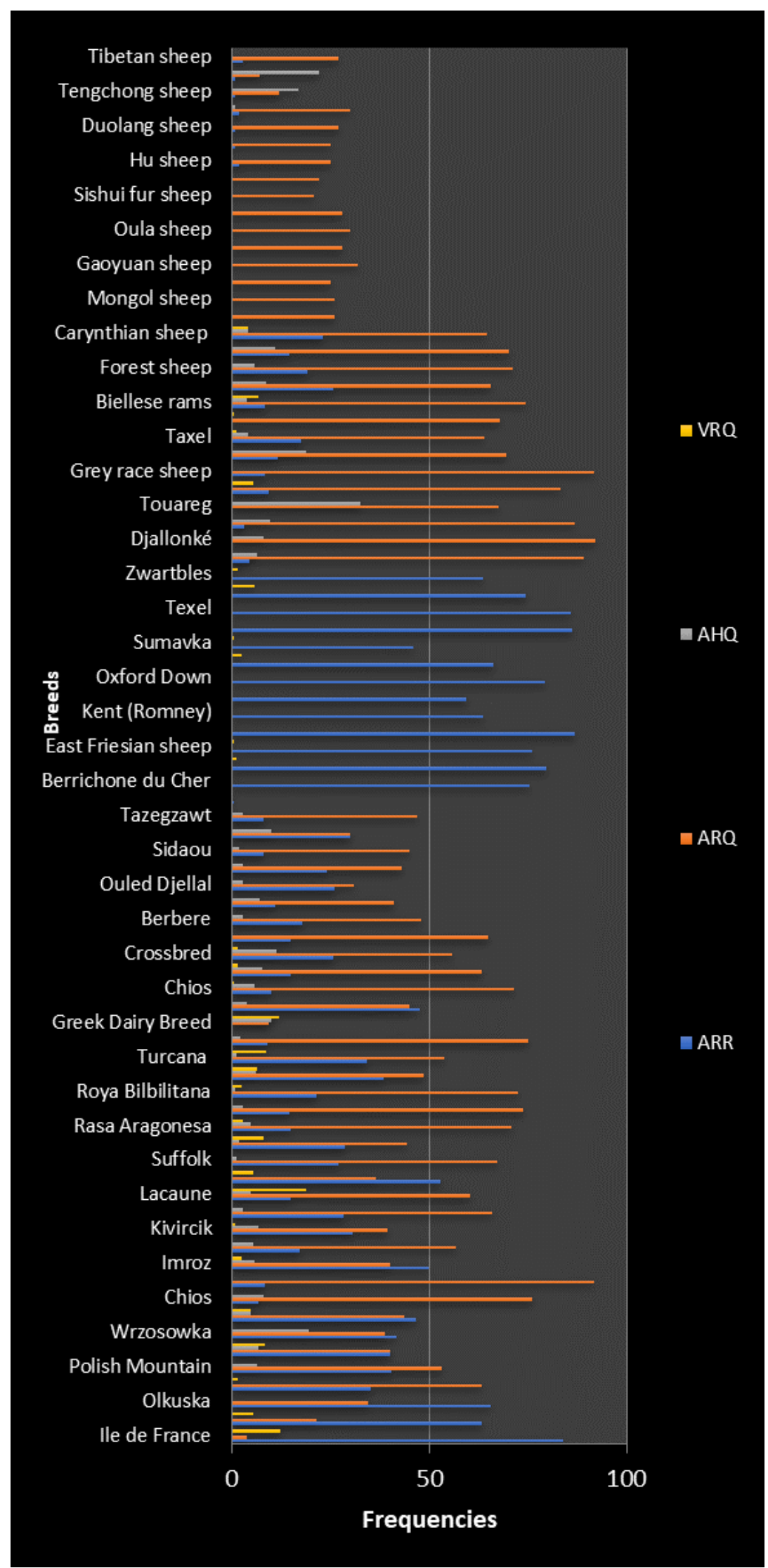

Figure 4. Haplotype frequencies of PRNP gene at codons 136, 154 and 171. (Constructed from Table 6) 


\section{Summary}

The purpose of this review is to highlight the countries where scrapie is causing problems and provide some information about the countries where scrapie is not present but there is possibility of its occurrence because scrapie is a prion disease and scientists still do not know how to cure the disease. It is very difficult to get rid of this if once entered in a country, the complete rid is only possible with the help of special breeding programs. Almost every country is working hard on breeding programs to get rid of scrapie, because these breeding programs showed positive signs in countries like Australia and New Zealand which are now scrapie free. But actual facts of scrapie in many parts of the world remain unknown due to the unsatisfactory passive surveillance system, because of which we cannot get consistent results or conclusion. As already described scrapie or any other prion disease do not have any treatment, so the only way to protect the animals is taking proper precautionary measures. The causative agent of the scrapie has still not been fully identified. All routes of transmission and their relative importance are still unknown. Animal health is directly related to humans, for the safety of humans, we must try to find some serious solutions for the well-being of animals. Like in humans, for the early diagnosis of sCJD many scientists have preferred the polysomnogram to detect earlier changes in SCJD patients may be praiseworthy. In humans, the accessory examinations of magnetic resonance imaging (MRI), electroencephalography (EEG), combined with this evidence and clinical symptom; scientists made a clinical diagnosis of sCJD. Though various drugs have been tried in vitro and/or in vivo, only four drugs have been studied in larger-scale observational or placebo-control trials: flupirtine, quinacrine, pentosan polysulfate (PPS), and doxycycline (Trevitt and Collinge, 2006). In sheep scientists must try some special drugs, any kind of hormonal changes which can prolong the survival or try to find any other way by which animal can show the clinical signs on early stage so that they can be culled or separated from healthy animals. Continuous study and research programs are needed to clear risk factor especially those affecting for human health. Yet, we do not have effective results which can lead us to the solution. The only possible solution is to carry out proper breeding programs. Continuity investigation is needed on this research for the well-being of the mankind and for the well-being of the animals. Further studies are needed to clarify the transmission of scrapie to humans.

Acknowledgements. This review is part of a project that is funded by Yunnan Provincial Key Research and Development Project (2018BB002).

\section{REFERENCES}

[1] Acín, C., Martín-Burriel, I., Goldmann, W., Lyahyai, J., Monzon, M., Bolea, R., Smith, A., Rodellar, C., Badiola, J. J., Zaragoza, P. (2004): Prion protein gene polymorphisms in healthy and scrapie-affected Spanish sheep. - Journal of General Virology 85(7): 21032110.

[2] Acutis, P., Sbaiz, L., Verburg, F., Riina, M., Ru, G., Moda, G., Caramelli, M., Bossers, A. V. (2004): Low frequency of the scrapie resistance-associated allele and presence of lysine-171 allele of the prion protein gene in Italian Biellese ovine breed. - Journal of General Virology 85(10): 3165-3172. 
[3] Adams, D., Caspary, E. (1968): Incorporation of nucleic acid and polysaccharide precursors into a post-ribosomal fraction of scrapie-affected mouse brain. - Biochemical Journal 108(5).

[4] Aiken, J. M., Williamson, J. L., Borchardt, L. M., Marsh, R. J. (1990): Presence of mitochondrial D-loop DNA in scrapie-infected brain preparations enriched for the prion protein. - Journal of Virology 64(7): 3265-3268.

[5] Alper, T., Haig, D. A., Clarke, M. C. (1966): The exceptionally small size of the scrapie agent. - Biochem Biophys Res Commun 22: 278-284.

[6] Alper, T., Cramp, W., Haig, D. A., Clarke, M. C. (1967): Does the agent of scrapie replicate without nucleic acid? - Nature 214(5090): 764.

[7] Alper, T., Haig, D., Clarke, M. (1978): The scrapie agent: evidence against its dependence for replication on intrinsic nucleic acid. - Journal of General Virology 41(3): 503-516.

[8] Andrade, C. P., Barbosa Neto, J. D., Driemeier, D. (2018): Identification of single nucleotide polymorphisms in the prion protein gene in Santa Ines and Dorset sheep. Pesquisa Veterinária Brasileira 38(4): 624-628.

[9] Babar, M. E., Farid, A., Benkel, B. F., Ahmad, J., Nadeem, A., Imran, M. (2009): Frequencies of PrP genotypes and their implication for breeding against scrapie susceptibility in nine Pakistani sheep breeds. - Molecular Biology Reports 36(3): 561565 .

[10] Bastian, F. O. (1979): Spiroplasma-like inclusions in Creutzfeldt-Jakob disease. Archives of Pathology and Laboratory Medicine 103(13): 665-669.

[11] Baylis, M., Chihota, C., Stevenson, E., Goldmann, W., Smith, A., Sivam, K., Tongue, S., Gravenor, M. J. (2004): Risk of scrapie in British sheep of different prion protein genotype. - Journal of General Virology 85(9): 2735-2740.

[12] Benkel, B. F., Valle, E., Bissonnette, N., Farid, A. H. (2007): Simultaneous detection of eight single nucleotide polymorphisms in the ovine prion protein gene. - Molecular and Cellular Probes 21(5-6): 363-367.

[13] Billinis, C., Psychas, V., Leontides, L., Spyrou, V., Argyroudis, S., Vlemmas, I., Leontides, S., Sklaviadis, T., Papadopoulos, O. J. (2004): Prion protein gene polymorphisms in healthy and scrapie-affected sheep in Greece. - Journal of General Virology 85(2): 547-554.

[14] Boukouvala, E., Gelasakis, A. I., Kanata, E., Fragkiadaki, E., Giadinis, N. D., Palaska, V., Christoforidou, S., Sklaviadis, T., Ekateriniadou, L. V. (2018a): The association between $171 \mathrm{~K}$ polymorphism and resistance against scrapie affection in Greek dairy sheep. - Small Ruminant Research 161: 51-56.

[15] Boukouvala, E., Katharopoulos, E., Christoforidou, S., Babetsa, M., Ekateriniadou, L. (2018b): Analysis of the PRNP gene polymorphisms in healthy Greek sheep during 2012-2016. - Small Ruminant Research 69(1): 839-846.

[16] Brotherston, J., Renwick, C., Stamp, J., Zlotnik, I., Pattison, I. J. (1968): Spread of scrapie by contact to goats and sheep. - Journal of Comparative Pathology 78(1): 9-17.

[17] Clouscard, C., Beaudry, P., Elsen, J., Milan, D., Dussaucy, M., Bounneau, C., Schelcher, F., Chatelain, J., Launay, J., Laplanche, J. (1995): Different allelic effects of the codons 136 and 171 of the prion protein gene in sheep with natural scrapie. - Journal of General Virology 76(8): 2097-2101.

[18] Comber, T. (1772): Real improvements in agriculture: (on the principles of A. Young, Esq.) recommended to accompany improvements of rents. - In a letter to Reade Peacock, esq; alderman of Huntingdon. To which is added, a letter to Dr. Hunter, physician in York. Concerning the rickets in sheep. Printed for W. Nicoll.

[19] Coşier, V., Vlaic, A., Vioara, M., Constantinescu, R. (2011): The genetic resistance of rams from Turcana breed to Ovine Transmissible Spongiform Encephalopathy (scrapie).

- RBL 16(4): 6328-6335. 
[20] Cosseddu, G., Agrimi, U., Pinto, J., Schudel, A. (2007): Advances in scrapie research. Revue scientifique et technique-Office international des épizooties 26(3): 657.

[21] Cuillé, J., Chelle, P.-L. (1938): La tremblante du mouton est-elle déterminée par un virus filtrable. - CR Acad Sci (Paris) 206: 1687-1688.

[22] de Mouton, T. (2007): Species Affected. www-cfsph.sws.iastate.edu. pp 1-14.

[23] DeSilva, U., Guo, X., Kupfer, D. M., Fernando, S. C., Pillai, A. T. V., Najar, F. Z., ... Roe, B. A. (2003): Allelic variants of ovine prion protein gene (PRNP) in Oklahoma sheep. - Cytogenetic and Genome Research 102(1-4): 89-94.

[24] Detwiler, L. A., Baylis, M. (2003): The epidemiology of scrapie. - Revue Scientifique Et Technique - Office International Des Epizooties 22(1): 121-144.

[25] Dickinson, A. G. (1979): The scrapie replication-site hypotheses and its implications for pathogenesis. - Slow Transmissible Diseases of the Nervous System 2: 13-31.

[26] Diener, T. O. (1972): Is the scrapie agent a viroid? - Nature New Biology 235(59): 218219.

[27] Djaout, A., Chiappini, B., Afri-Bouzebda, F., Conte, M., Chekkal, F., El-Bouyahiaoui, R., ... Vaccari, G. (2018): Biodiversity and selection for scrapie resistance in sheep: genetic polymorphism in eight breeds of Algeria. - Journal of Genetics 97(2): 453-461.

[28] Erdt, W. E. A. (1861): Die Traberkrankheit der Schafe, ihre Natur, Genesis, Erkennung, Ursachen, Verhütung und Ausrottung. - Bosselmann, Berlin.

[29] Frank, E. C. (1820): Beschluß der gesammelten Erfahrungen über die Traberkrankheit der Schafe. - Verhandlungen der Königlich sächsischen ökonomischen Gesellschaft 10-24.

[30] Gibbons, R. A., Hunter, G. D. (1967): Nature of the scrapie agent. - Nature 215(5105): 1041-1043.

[31] Goldmann, W. (2008): PrP genetics in ruminant transmissible spongiform encephalopathies. - Veterinary Research 39(4): 1-14.

[32] Goldmann, W., Baylis, M., Chihota, C., Stevenson, E., Hunter, N. (2005): Frequencies of PrP gene haplotypes in British sheep flocks and the implications for breeding programmes. - Journal of Applied Microbiology 98(6): 1294-1302.

[33] Greenlee, J. J. (2019): Update on classical and atypical scrapie in sheep and goats. Veterinary Pathology 56(1): 6-16.

[34] Griffith, J. S. (1967): Nature of the scrapie agent: self-replication and scrapie. - Nature 215(5105): 1043-1044.

[35] Hautaniemi, M., Tapiovaara, H., Korpenfelt, S. L., Sihvonen, L. (2012): Genotyping and surveillance for scrapie in Finnish sheep. - BMC Veterinary Research 8(1): 122.

[36] Hering, E. (1849): Specielle Pathologie und Therapie für Thierärzte: zum Gebrauche bei Vorlesungen und zu eigener Belehrung. - Ebner \& Seubert, Stuttgart.

[37] Houston, F., Goldmann, W., Foster, J., Gonzalez, L., Jeffrey, M., Hunter, N. (2015): Comparative susceptibility of sheep of different origins, breeds and PRNP genotypes to challenge with bovine spongiform encephalopathy and scrapie. - PloS One 10(11).

[38] Hunter, N. (1997): Molecular biology and genetics of scrapie in sheep. - The Genetics of Sheep 225-240.

[39] Hunter, N., Foster, J. D., Goldmann, W., Stear, M. J., Hope, J., Bostock, C. (1996): Natural scrapie in a closed flock of Cheviot sheep occurs only in specific PrP genotypes. - Archives of Virology 141(5): 809-824.

[40] EFSA (2014): Scientific opinion on the scrapie situation in the EU after 10 years of monitoring and control in sheep and goats. - EFSA Journal 12(7): 3781.

[41] EFSA (2017): The European Union summary report on surveillance for the presence of transmissible spongiform encephalopathies (TSE) in 2016. - EFSA Journal15(11): e05069.

[42] EFSA (2018): The European Union summary report on surveillance for the presence of transmissible spongiform encephalopathies (TSE s) in 2017. - EFSA Journal 16(11): e05492. 
[43] Kaczor, U., Domoń, D., Martyniuk, E., Murawski, M. (2011): Polymorphism in the PRNP locus in prolific Olkuska sheep. - Bulletin of the Veterinary Institute in Puławy 55(1): 3-7.

[44] Karami, M., Amirinia, C., Kashan, N. E., Amirmozafari, N., Chamani, M., Banabazi, M. H. (2011): Polymorphisms of the prion protein gene Arabi sheep breed in Iran. - African Journal of Biotechnology 10(70): 15819-15822.

[45] Kioutsioukis, C., Papadogiannakis, E., Palaska, V., Kontos, V., Papakostaki, D., Paraskeva, S., Vassalou, E. (2018): Prion protein gene polymorphisms in classical scrapie-affected flocks of sheep in Central Macedonia. - Journal of the Hellenic Veterinary Medical Society 69(2): 931-940.

[46] Kutzer, T., Pfeiffer, I., Brenig, B. (2002): Identification of new allelic variants in the ovine prion protein (PrP) gene. - Journal of Animal Breeding and Genetics 119(4): 201208.

[47] Lan, X. Y., Zhao, H. Y., Li, Z. J., Li, A. M., Lei, C. Z., Chen, H., Pan, C. Y. (2012): A novel 28-bp insertion-deletion polymorphism within goat PRNP gene and its association with production traits in Chinese native breeds. - Genome 55(7): 547-552.

[48] Lan, Z., Li, J., Sun, C., Liu, Y., Zhao, Y., Chi, T., ... Wang, Z. (2014): Allelic variants of PRNP in 16 Chinese local sheep breeds. - Archives of Virology 159(8): 2141-2144.

[49] Lan, Z., Wang, Z. L., Liu, Y., Zhang, X. (2006): Prion protein gene (PRNP) polymorphisms in Xinjiang local sheep breeds in China. - Archives of Virology 151(10): 2095-2101.

[50] Lee, C. A., Ironside, J. W., Bell, J. E., Giangrande, P., Ludlam, C., Esiri, M. M., McLaughlin, J. E. (1998): Retrospective neuropathological review of prion disease in UK haemophilic patients. - Thrombosis and Haemostasis 80(12): 909-911.

[51] Leontides, S., Psychas, V., Aargyroudis, S., Giannati-Stefanou, A., Paschaleri-Papadopoulou, E., Manousis, T., Sklaviadis, T. (2000): A survey of more than 11 years of neurologic diseases of ruminants with special reference to transmissible spongiform encephalopathies (TSEs) in Greece. - Journal of Veterinary Medicine, Series B 47(4): 303-309.

[52] Liu, Y. Z., Zhao, C. L., Yang, Y. Z., Wu, R., Wang, C., Wan, X. R., Wang, Y. (2017): The correlation analysis of polymorphisms of Prion-Related Doppel (PRND) with prion (PRNP) alleles in Gansu Alpine Merino sheep. - Genetics and Molecular Research 16(4).

[53] Lühken, G., Lipsky, S., Peter, C., Erhardt, G. (2008): Prion protein polymorphisms in autochthonous European sheep breeds in respect to scrapie eradication in affected flocks. - Small Ruminant Research 75(1): 43-47.

[54] M'Gowan, J. P. (1914): Investigation into the Disease of Sheep called "Scrapie" (Traberkrankheit; La Tremblante) with Especial Reference to its Association with Sarcosporidiosis. With an Appendix on a Case of Johne's Disease in the Sheep. William Blackwood and Sons, Edinburgh.

[55] Mabbott, N. A. (2017): How do PrPSc prions spread between host species, and within hosts? - Pathogens 6(4): 60.

[56] Manuelidis, L. J. (1996): In the Community of Dinosaurs: The Viral View. - In: Court, L, Dodet, B. (eds.) Transmissible Subacute Spongiform Encephalopathies: Prion Diseases. Elsevier, Paris, pp. 375-387.

[57] Mari, K. B. (2016): Genetics of scrapie susceptibility in females of Tsigai Breed. Doctoral Dissertation, Szent István University, Faculty of Veterinary Science, Budapest.

[58] May, G. (1868): Das Schaf: seine Wolle, Racen, Züchtung, Ernährung u. Benutzung, sowie dessen Krankheiten: in 2 Bd (Vol. 1). - Trewendt, Breslau.

[59] Mesquita, P., Batista, M., Marques, M. R., Santos, I. C., Pimenta, J., Silva Pereira, M., ... Fontes, C. M. (2010): Prion-like Doppel gene polymorphisms and scrapie susceptibility in Portuguese sheep breeds. - Animal Genetics 41(3): 311-314. 
[60] Oesch, B., Westaway, D., Wälchli, M., McKinley, M. P., Kent, S. B., Aebersold, R., ... Prusiner, S. B. (1985): A cellular gene encodes scrapie PrP 27-30 protein. - Cell 40(4): 735-746.

[61] Oner, Y., Yesilbag, K., Tuncel, E., Elmaci, C. (2011): Prion protein gene (PrP) polymorphisms in healthy sheep in Turkey. - Animal 5(11): 1728-1733.

[62] Otelea, M. R., Zaulet, M., Dudu, A., Otelea, F., Baratareanu, S., Danes, D. (2011): The scrapie genetic susceptibility of some sheep breeds in southeast Romanian area and genotype profiles of sheep scrapie infected. - Romanian Biotechnology Letter 16(4): 6419-6429.

[63] Pattison, I. H., Jones, K. M. (1967): The possible nature of the transmissible agent of scrapie. - Veterinary Record 80(1): 2-9.

[64] Pattison, I. H., Millson, G. C. (1961): Experimental transmission of scrapie to goats and sheep by the oral route. - Journal of Comparative Pathology and Therapeutics 71: 171176.

[65] Prusiner, S. B. (1982): Novel proteinaceous infectious particles cause scrapie. - Science 216(4542): 136-144.

[66] Psifidi, A., Basdagianni, Z., Dovas, C. I., Arsenos, G., Sinapis, E., Papanastassopoulou, M., Banos, G. (2011): Characterization of the PRNP gene locus in Chios dairy sheep and its association with milk production and reproduction traits. - Animal Genetics 42(4): 406-414.

[67] Ribbe, J. C. (1821): Die innerlichen und äusserlichen Krankheiten des Schafviehes und deren Heilung: mit Bezug auf die Verhütung und Abwendung dieser Uebel wissenschaftlich-praktisch für gebildete Leser dargestellt: nebst einem Anhange zum Unterricht für Schäfer. - Barth, Leipzig.

[68] Sigurdsson, B. (1954): Rida, a chronic encephalitis of sheep: with general remarks on infections which develop slowly and some of their special characteristics. - British Veterinary Journal 110(9): 341-354.

[69] Sipos, W., Kraus, M., Schmoll, F., Achmann, R., Baumgartner, W. (2002): PrP genotyping of Austrian sheep breeds. - Journal of Veterinary Medicine Series A 49(8): 415-418.

[70] Stepanek, O., Horin, P. (2017): Genetic diversity of the prion protein gene (PRNP) coding sequence in Czech sheep and evaluation of the national breeding programme for resistance to scrapie in the Czech Republic. - Journal of Applied Genetics 58(1): 111121.

[71] Szkudlarek-Kowalczyk, M., Wiśniewska, E., Milewski, S. T. A. N. I. S. Ł. A. W., Mroczkowski, S. Ł. A. W. O. M. I. R. (2010): Prion protein gene (PRNP) polymorphism in a flock of sheep of Kamieniecka breed. - Bulletin of the Veterinary Institute in Pulawy 54: 645-649.

[72] Hanušovská, E., Novák, M., Arvayová, M., Mikula, I. (2003): The PrP genotype of sheep of the improved Valachian breed. - Folia Microbiologica 48(2): 269-276.

[73] Tongue, S. C., Wilesmith, J. W., Cook, C. J. (2004): Frequencies of prion protein (PrP) genotypes and distribution of ages in 15 scrapieaffected flocks in Great Britain. Veterinary Record 154(1): 9-16.

[74] Traoré, A., L. J., Kaboré, A., Pérez-Pardal, L., Álvarez, I., Fernández, I., ... Goyache, F. (2012): Prion protein gene polymorphism in four West African sheep populations. Tropical Animal Health and Production 44(7): 1469-1472.

[75] Trevitt, C. R., Collinge, J. (2006): A systematic review of prion therapeutics in experimental models. - Brain 129(9): 2241-2265

[76] Ugarte, E., Gabina, D. U. N. I. X. I. (2004): Recent developments in dairy sheep breeding. - Archiv für Tierzucht 47(6; SPI): 10-17.

[77] Van Duijn, C. M., Delasnerie-Laupretre, N., Masullo, C., Zerr, I., De Silva, R., Wientjens, D. P. W. M., ... Alperovitch, A. (1998): Case-control study of risk factors of Creutzfeldt-Jakob disease in Europe during 1993-95. - Lancet 351(9109): 1081-1085. 
[78] Wagenfeld, L. (1829): Ueber die Erkennung und Cur der Krankheiten der Schaafe. Gerhard, Danzig.

[79] Weissmann, C. (1991): A 'unified theory’ of prion propagation. - Nature 352(6337): 679683.

[80] White, S., Herrmann-Hoesing, L., O'rourke, K., Waldron, D., Rowe, J., Alverson, J. (2008): Prion gene (PRNP) haplotype variation in United States goat breeds (Open Access publication). - Genetics Selection Evolution 40(5): 553-561.

[81] Wiśniewska, E., Mroczkowski, S. (2009): Different breeding strategies for scrapie resistance depending on breed-specific PrP allele and genotype frequencies in the Polish sheep. - Züchtungskunde 81(3): 180-189.

[82] Wiśniewska, E., Lühken, G., Mroczkowski, S., Erhardt, G. (2006): Prion protein (PrP) gene polymorphisms and breeding for resistance to scrapie in Polish Merino sheep. Arch Tierz 49: 365-371.

[83] Yaman, Y., Ün, C. (2017): Genetic Resistance to Prion Diseases. - In: Tutar, Y. (ed.) Prion - An Overview. IntechOpen, London.

[84] Yang, Q., Zhang, S., Liu, L., Cao, X., Lei, C., Qi, X., ... Wang, R. (2016): Application of mathematical expectation (ME) strategy for detecting low frequency mutations: an example for evaluating 14-bp insertion/deletion (indel) within the bovine PRNP gene. Prion 10(5): 409-419.

[85] Yang, Q., Zhang, S., Liu, L., Lei, C., Qi, X., Lin, F., ... Chen, H. (2018): The evaluation of 23-bp and 12-bp insertion/deletion within the PRNP gene and their effects on growth traits in healthy Chinese native cattle breeds. - Journal of Applied Animal Research 46(1): 505-511.

[86] Zhou, R., Li, X., Xi, J., Li, L., Zhang, Z., Zhao, Z. (2013): Genetic variability of PRNP in Chinese indigenous goats. - Biochemical Genetics 51(3-4): 211-222. 